\title{
FINANCIAL CYCLES IN THE ECONOMY AND IN ECONOMIC RESEARCH: A CASE STUDY IN CHINA
}

\author{
Yong QIN ${ }^{1}$, Zeshui XU ${ }^{1 *}$, Xinxin $\mathrm{WANG}^{1 \#,}$ \\ Marinko ŠKARE ${ }^{2}$, Małgorzata PORADA-ROCHOŃ ${ }^{3}$ \\ ${ }^{1}$ Business School, Sichuan University, 610064 Chengdu, China \\ ${ }^{2}$ Faculty of Economics \& Tourism "Dr Mijo Mirkovic", Juraj Dobrila University Pula, \\ Preradoviceva 1/1, 52100 Pula, Croatia \\ ${ }^{3}$ Faculty of Economics, Finance and Management, University of Szczecin, Szczecin, Poland
}

Received 12 August 2020; accepted 09 June 2021

\begin{abstract}
This work explores the relationship between financial cycles in the economy and in economic research. To this aim, we take China as an empirical example, and an intuitive bibliometric analysis of selected terms concerning financial cycles in economic research is performed first. Both in the economy and in economic research, we then conduct singular spectrum analysis to further isolate and describe the specific length and amplitude of financial cycles for China based on quarterly time-series data. Finally, according to the estimated cycles that detrended by Hodrick-Prescott filter for financial and bibliometric variables, the Granger causality test scrutinizes the results of the first two steps. Moreover, a time-varying parameter vector autoregression model is estimated to quantitatively investigate the time-varying interaction between financial and bibliometric variables. Our study shows that financial cycles have a strong effect on the developments in the financial-related literature. In particular, the 2008 global financial crisis's impulse intensity is significantly higher than in other periods. Surprisingly, discussions on financial cycles in the literature also have an impact on financial activities in real life. These findings contribute to nascent work on the patterns in financial cycles, thus providing a new and effective insight on the interpretation of financial activities.
\end{abstract}

Keywords: financial cycles, bibliometric analysis, singular spectrum analysis, Granger causality test, TVP-VAR model.

JEL Classification: C32, C58, G01, G1, G17.

\section{Introduction}

Financial cycles play a significant role in the macroeconomic dynamics of modern economies and have a great impact on real economic activities around the world (Schularick \& Taylor, 2009). In the last few decades, several financial events with a wide-ranging effect broke out,

*Corresponding author. E-mail: xuzeshui@263.net

\#Corresponding author. E-mail: wangxinxin_cd@163.com

Copyright (c) 2021 The Author(s). Published by Vilnius Gediminas Technical University

This is an Open Access article distributed under the terms of the Creative Commons Attribution License (http://creativecommons. org/licenses/by/4.0/), which permits unrestricted use, distribution, and reproduction in any medium, provided the original author and source are credited. 
from the asset market crash in the early 1990s, the Asian financial turmoil in 1997, to the global financial crisis in 2008. Some argue that financial cycles are intrinsic to business cycles (Borio, 2017). However, in contrast with business cycles, recessions concerned with financial disruptions are deeper and long-lasting (Shen et al., 2019). For this reason, an intensive debate on the concept and nature of financial cycles sprang up from researchers and policymakers (Lee et al., 2017). Characterizing financial cycles from empiricism and theory has increasingly become a significant research field (Claessens et al., 2011; Strohsal et al., 2019b).

To help policymakers and financial practitioners have a better understanding of financial cycles, in turn, plan practical response policies. There is a growing body of literature that captures and measures financial cycles, especially the average length and amplitude. Successfully tracking financial cycles engages the need to select a suitable empirical method or technique. Claessens et al. (2011) conducted an empirical analysis of the quarterly data for 21 advanced OECD countries from 1960 to 2007 using the turning point analysis. They concluded that financial cycles are highly synchronized between countries. Using the same approach, Farrell and Kemp (2020) identified financial cycles via detecting peaks and troughs in the individual component variables that make up the cycle. Benchmark methods based on frequency-based filters are generally employed to measure financial cycles. Drehmann et al. (2012) discussed the behavior of financial cycles for seven countries by combining the analysis of turning points and the band-pass filter technique. The results showed that financial cycles are much longer than traditional business cycles. Using the band-pass filter technique, Aikman et al. (2015) isolated the credit cycle and got similar results. Pontines (2017) measured financial cycles for four East Asia economies using available data. The results suggested that financial cycles in these economies are operating at low frequencies, which is nearly consistent with those for observed advanced economies. Also, non-parametric methods in the frequency domain offer an effective way. Strohsal et al. (2019a) implemented a multivariate parametric frequency domain analysis and provided evidence on the cross-country interaction of financial cycles. Yan and Huang (2020) estimated the length of the period of financial cycles for the USA and further verified the theory in financial cycles.

Recently, the application of the singular spectrum analysis (SSA) technique is emerging to measure financial cycles. Škare and Porada-Rochon (2019) applied SSA to isolate and track financial cycles within ten transitional economies from 2005 to 2018. The results proved the superiorities of SSA in the research of financial cycles. Škare and Porada-Rochon (2020) traced financial cycles for ten selected economies by using multi-channel singular-spectrum analysis (MSSA) from 1970 to 2018. Their study showed that a global financial cycle lasts nine years on average with long-memory properties.

Another significant aspect of financial cycles that has received much attention in recent years is that the influence of financial cycles across countries. According to Rey (2013), financial cycles co-moved with the VIX (a measure for market uncertainty and risk aversion). They applied a vector autoregressive (VAR) analysis to study the impacts of financial cycles on capital flows, credit growth and global banks. Based on the same method, the comovement among financial cycles, business cycles and monetary policy in the USA was studied by Juselius et al. (2016). Still, Wen et al. (2019) examined the time-varying impact of financial cycles on oil prices via the time-varying parameter (TVP-VAR). They found that the connec- 
tion between financial markets and crude oil prices is strengthened during the 2008 global financial crisis. We could find related research in Brem et al. (2020), Pagan and Robinson (2014), and Yépez (2018). However, only a few focus research on the connection and causality between financial cycles in the economy and in economic research.

Against this background, the goal of this paper is to investigate the relationship between financial cycles in the economy and in economic research. Put differently, whether there are patterns in economic research regarding financial cycles, and whether these are associated with the movement in actual financial activity. Some previous relevant work has initially shed light on this question. Geiger (2014) provided a quantitative assessment manner (i.e., a bibliometric analysis) to explore the rise of behavioral economics in the academic literature. This work revealed a potential cyclicality in the literature based on SSCI and JSTOR data. Later, the links between business cycles in the economy and economics were confirmed by Geiger and Kufenko (2016) through the VAR model and Granger causality test. By the same token, evidence from econometric analysis witnessed the impact of poverty cycles on economic research and the relationship between the literature on family firms and actual movements in economic policy and activities (Qin et al., 2020, 2021).

Motivated by the above research, it aims at answering the following three specific questions in this paper. Firstly, are there certain characteristics, trends or patterns in the related literature on financial cycles? Secondly, what is the particular length of financial cycles in the literature? Is it synchronized with the actual financial cycles? Thirdly, are financial activities in the economy correlated with the development of related literature on financial cycles? More to the point, is there any impact of financial cycles in reality on financial cycles in the literature? To tackle these issues, we conduct a case study of China by aggregating several empirical approaches over a long period.

For the first question, following the study of Geiger (2014), a detailed bibliometric analysis of selected key terms is provided concerning financial cycles in journal articles concerning CNKI data. This method allows us to observe the features of the development of financialrelated literature visually. It highlights two intuitive facts. One is that the timing of large fluctuations in the number of publications exactly corresponds to the outbreak of relevant financial crises or events. The other is that almost all series reach a peak during the 2008 global financial crisis. SSA model is used to deal with the second question in this paper. As a result, a univariate analysis of proxy variables is conducted for financial cycles, from both in the economy and in economic research. The results indicate that the average length of financial cycles in the economy is nearly the same as in the literature. Regarding the third question, we follow the study of Geiger and Kufenko (2016). To estimate respective cycles, time series for six common financial indicators in China and 17 bibliometric series are detrended by Hodrick-Prescott (HP) filter. Then, the Granger causality test is employed to detect the comovement between financial activities and developments in economic research regarding financial cycles. We add an investigation of the time-varying effects of selected financial indicators on two bibliometric variables via a trivariate TVP-VAR model. Interestingly, the results are consistent with our expectations.

The contribution of this paper is threefold. First, our study is among the few (if any) to track and isolate financial cycles in the financial-related literature. Therefore, this work offers 
a pivotal insight into cyclical patterns and characteristics of financial-related literature. Second, we find Granger causalities from financial variables to bibliometric ones. Results directly point towards confirmation of the inference of an impact of financial cycles in the economy on relevant scientific works. Third, there are signs that there is an interaction between the state of finance in reality and developments in the academic literature. That is to say, the development patterns in the academic literature would also affect the actual financial activities in real life. Overall, these original work and interesting discoveries would help people predict the actual financial activities according to the oscillatory patterns in the scientific activity. More importantly, policymakers could make timely and accurate response strategies by perceiving the changes in the financial-related literature and thereby guide the unfolding of relevant financial work.

We structure the rest of this paper: Section 1 presents the materials and method. In Section 2, we give empirical results and related discussions. Finally, we draw some conclusions from our study in the last Section.

\section{Materials and methods}

To analyze and estimate financial cycles in real economic activities and financial research, meanwhile, the relationship between financial activities and the financial-related literature in China, the respective proxy variables for financial cycles are described at first. We elaborate on the empirical methods, including bibliometric analysis, singular spectrum analysis and econometric methods. Figure 1 illustrates the entire research framework and process of this study.

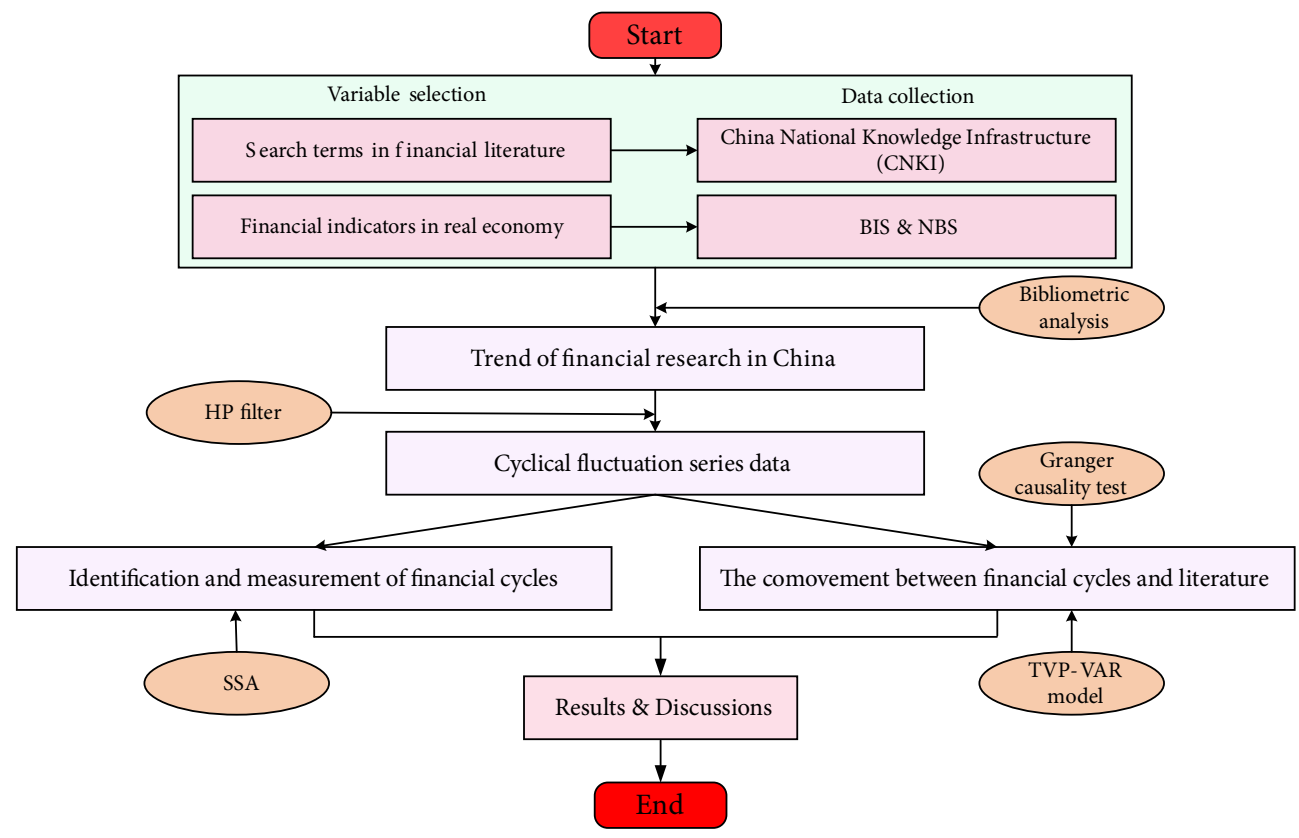

Figure 1. The research framework and process of this study (source: authors' own model) 


\subsection{Variable description}

This study follows a case-study design, with an in-depth analysis of the links and comovement between financial cycles and financial research in China. Therefore, we need to select variables, namely financial indicators in the real economy and search terms in the economic literature on financial cycles, to evaluate the corresponding cycles.

Initially, we determine the proxy indicators on financial cycles in the real economy. It is widely recognized that financial cycles cannot be identified and characterized without credit, house prices and asset prices (Shen et al., 2019). Meanwhile, the proxy indicators for financial cycles assessment are also relevant to financial recessions, i.e., the depressions that coincide with banking crises (Jordà et al., 2013; Schüler et al., 2020). Claessens et al. (2011) pointed out that credit, house prices and equity prices are the three central indicators to capture financial cycles. Later, Drehmann et al. $(2012,2013)$ established a more comprehensive financial cycle indicator system: credit to the private non-financial sector, credit-to-GDP ratio, equity prices and house price index. As a result, financial cycles of seven countries over the period 1960 to 2011 were depicted with quarterly data. Financial variables or indicators, such as bond prices and purchasing managers' index (PMI), are also considered in the literature. For instance, Rozite et al. (2019) took PMI into account and discussed financial cycles for the USA. For a broad measure of financial cycles regarding G-7 countries, Schüler et al. (2020) highlighted that the bond prices should also be included. Building on these fertile studies, in the univariate analysis of financial cycles for China, we aggregate the above widely accepted proxy indicators, i.e., credit-to-GDP ratio, credit to private non-financial sector, house price index, bond prices, equity prices and $P M I$, and use quarterly time-series data to estimate financial cycles in this paper.

After we select the variables, we gather essential data for all variables. If we choose a uniform period, we will lose some variable observations. Thus, the length of the time-series data is not restricted and limited in this study. We standardize the series using logarithm transformation. The credit-to-GDP ratio is expressed in percentage of credit to the private non-financial sector in GDP. The credit to the private non-financial sector is from all sectors. Here, we adopt the house sale price index to represent the house price index. As for bond prices, we use the China bond composite index for its integrity. Considering the sample size, we use the most extended series, namely Shanghai (securities) composite index, to portray equity prices. $P M I$, as a significant economic indicator, well capture finance and real sector linkages. Given the availability of data, we apply manufacturing PMI in this paper. For simplicity, these six variables are denoted by different notations, as shown in Table 1 . The time frame and data source for each variable are also listed.

Next, we need to select search terms in the literature to identify financial cycles in economic research. After looking through abundant relevant literature, combining the actual situation in China simultaneously, we finally establish 16 key search terms, i.e., "bank", "bond", "capital”, “credit”, “crisis”, “currency”, “cycle”, “dollar”, “equity”, “finance”, "government”, “market", "policy", "house", "trade" and "trustworthiness". In terms of literature sources, nowadays, there exist various and multiform electronic literature databases in China, which provide us with a wealth of choices and fruitful experimental samples. For example, CNKI (China National Knowledge Infrastructure), VIP and WanFang Chinese databases are widely known 
Table 1. Definition and sources of financial variables (source: authors' own model from the listed databases)

\begin{tabular}{|c|c|c|c|c|}
\hline $\begin{array}{l}\text { Financial } \\
\text { variables }\end{array}$ & Notations & Description & Sample length & Data sources \\
\hline $\begin{array}{l}\text { LN (Credit- } \\
\text { to-GDP } \\
\text { ratio) }\end{array}$ & $C G$ & $\begin{array}{l}\text { Credit to the private } \\
\text { non-financial sector } \\
\text { (percentage of GDP) }\end{array}$ & 1985 Q4-2019 Q3 & \multirow{2}{*}{$\begin{array}{l}\text { Bank for International } \\
\text { Settlements (https://www.bis.org/) }\end{array}$} \\
\hline $\begin{array}{l}\text { LN (Credit } \\
\text { to the private } \\
\text { non-financial } \\
\text { sector) }\end{array}$ & $C P$ & $\begin{array}{l}\text { US dollar - } \\
\text { Adjusted for breaks }\end{array}$ & 1985 Q4-2019 Q3 & \\
\hline $\begin{array}{l}\text { LN (House } \\
\text { price index) }\end{array}$ & $H I$ & $\begin{array}{l}\text { House sale price } \\
\text { index }\end{array}$ & 1995 Q1-2019 Q3 & $\begin{array}{l}\text { https://www.bis.org/; } \\
\text { http://www.drcnet.com.cn/ }\end{array}$ \\
\hline $\begin{array}{l}\mathrm{LN} \text { (Bond } \\
\text { prices) }\end{array}$ & $B P$ & $\begin{array}{l}\text { China bond } \\
\text { composite index }\end{array}$ & 2002 Q1-2019 Q4 & https://www.chinabond.com.cn/ \\
\hline $\begin{array}{l}\text { LN (Equity } \\
\text { prices) }\end{array}$ & $E P$ & $\begin{array}{l}\text { Shanghai (securities) } \\
\text { composite index }\end{array}$ & 1991 Q1-2019 Q4 & $\begin{array}{l}\text { https://cn.investing.com/indices/ } \\
\text { shanghai-composite }\end{array}$ \\
\hline $\begin{array}{l}\text { LN } \\
\text { (Purchasing } \\
\text { managers' } \\
\text { index) }\end{array}$ & $P M I$ & Manufacturing PMI & 2005 Q1-2019 Q4 & $\begin{array}{l}\text { National Bureau of Statistics of } \\
\text { China (http://www.stats.gov.cn/) }\end{array}$ \\
\hline
\end{tabular}

and used by scholars. Among them, as the world's largest full-text information digital library, CNKI contains the wealthiest knowledge resources and the most effective knowledge dissemination and digital learning platform. In this light, CNKI is undoubtedly the best choice in this paper.

In all literature categories of CNKI, we shrink the search scope to the "Finance" group. In this way, the retrieved documents are more targeted. Also, we limit the literature type searching to academic journals, excluding dissertations, conferences and books. The reason is that journals, as the principal components of the literature, usually have timeliness and scientific characteristics. What is more, we usually publish the latest and most relevant research results in journals. Up to now, over 1,772,755 journal articles are archived in the "Finance" category. Because of the requirement of data continuity, we set the search time range to 1979-2019. For the choice of search manner in CNKI, we employ the form of "topic" search to get data in this paper, which usually makes the results more convincing. It needs to be clarified that, to a certain extent, the fluctuations in the total number of journal articles in the "Finance" category per se annually also reflect financial cycles in the literature. Hence, "Finance" itself is regarded as a variable and analyzed in this paper. Likewise, for the convenience of subsequent work, these search terms are symbolized. Table 2 offers the notations and corresponding references of literature variables.

Another point to notice is that the data frequency of literature variables is annual rather than quarterly. To be consistent with the time interval of financial variables, we apply the quadratic match average. As a result, the low-frequency annual data are transformed into high-frequency quarterly data. 
Table 2. Notations and references of literature variables (source: authors' own model)

\begin{tabular}{|c|l|l|}
\hline Notations & \multicolumn{1}{|c|}{ Literature variables } & \multicolumn{1}{|c|}{ References } \\
\hline$T L$ & Total & - \\
\hline$B K$ & Bank & Amiti et al. (2019) \\
\hline$B D$ & Bond & Mizen and Tsoukas (2012) \\
\hline$C L$ & Capital & Boisjoly et al. (2020), Inekwe and Valenzuela (2020) \\
\hline$C T$ & Credit & Pinheiro et al. (2017) \\
\hline$C S$ & Crisis & Fidrmuc and Korhonen (2010) \\
\hline$C Y$ & Currency & Yamani (2019) \\
\hline$C E$ & Cycle & Borio (2014) \\
\hline$D R$ & Dollar & Morana (2017) \\
\hline$E Y$ & Equity & Berger and Udell (1998) \\
\hline$F E$ & Finance & Ozili (2018) \\
\hline$G T$ & Government & Pragidis et al. (2018) \\
\hline$M T$ & Market & Beirne (2020) \\
\hline$P Y$ & Policy & Ouyang and Guo (2019) \\
\hline$H E$ & House & Martínez-García and Grossman (2020) \\
\hline$T E$ & Trade & Zouri (2020) \\
\hline$T S$ & Trustworthiness & Jetter and Kristoffersen (2018) \\
\hline & & \\
\hline
\end{tabular}

\subsection{Bibliometrics}

Bibliometrics, as a powerful literature analysis approach, allows the identification of trends observed in the topics, terms or sub-fields of a given scientific domain (Mourao \& Martinho, 2020; Yu et al., 2019). The bibliometric analysis emphasizes inspecting the publication's dispersed pattern, institutions and time distribution in a structured quantitative way (Muhammad et al., 2020). Initially, bibliometrics is restricted to the library and information science. With its ongoing development and improvement, it has been widely used in various subject areas to measure the research progress (Chen et al., 2017; Tunger \& Eulerich, 2018; Wang et al., 2021). For example, the innovation in Latin America was investigated from the perspective of bibliometrics (Cortés-Sánchez, 2019). Also, the connection between behavioral finance and decision making with cognitive biases was explored (Costa et al., 2017). Based on bibliometric indicators, the impact of the different granularity level in the classification of scientific fields on research evaluation was quantitatively estimated (Demetrescu et al., 2020). Through visual presentation, we can find the intellectual landscape of research knowledge in a brief time (Chen et al., 2014; Tandon et al., 2021). To capture and characterize the development trends about financial cycles in the scientific literature, we first apply bibliometric analysis to reveal the performance in the finance domain in China from 1979 to 2019.

\subsection{Singular spectrum analysis}

In this study, we use the method of univariate singular spectrum analysis (SSA) to isolate financial cycles in the real economy and in economic research using quarterly time-series data 
for China. SSA was put forward by Colebrook (1978) and used in oceanographic research initially. Then, it was developed by Vautard and Ghil (1989), Vautard et al. (1992), Allen and Smith (1996), Ghil et al. (2001) and Groth and Ghil (2015). It has been proven that SSA has strong superiority in processing short, chaotic and noisy time series (Škare \& PoradaRochon, 2019), naturally including the financial and literature time series data employed in this paper. Before using the SSA model, the data pre-process needs to be conducted, considering both financial and literature variables. We execute the same operation on literature variables, i.e., standardizing the series via logarithms. Afterward, we perform the HP filter to extract the cyclical components and divide the trends from the series (Hodrick \& Prescott, 1997). Because many trends in the series will distort the cross-correlation in the frequency domain (Škare \& Porada-Rochoń, 2020). As a result, with the help of SSA, the dominant cycle, namely the oscillatory pattern, for each variable is identified and captured.

Following prior studies, we decompose the variance into the eigenvectors $E_{k}$ and eigenvalues $\lambda k$ for our series, then

$$
c_{i j}=\frac{1}{N-|i-j|} \sum_{t=1}^{N-|i-j|} X(t) X(t+|i-j|),
$$

where $c_{i j}$ is the lag covariance matrix, $N$ refers to the number of data points in an observed time series, $i$ and $j$ denote the time indices, $t$ depicts the consecutive time and $X(t)$ represents the observed time series.

As shown in Eq. (1), it enables us to divide and extract the cycle's components, trends and random noise in the series. Based on the obtained eigenvectors and eigenvalues, we identify the principal components of the variance matrix via decomposing the series, i.e.,

$$
X=\left(\begin{array}{crrc}
x_{(1)} & x_{(2)} & \cdots & x_{(M)} \\
x_{(2)} & x_{(3)} & \cdots & x_{(M+1)} \\
\cdots & \cdots & & \cdots \\
x_{(N-M+1)} & x_{(N-M+2)} & \cdots & x_{(N)}
\end{array}\right),
$$

where $X$ denotes the univariate time series and $M$ depicts the embedded dimension.

As a result, the respective principal components (PCs) are acquired:

$$
H_{k}(t)=\sum_{j=1}^{M} X(t+j-1) \beta_{k}(j),
$$

where $\beta_{k}$ represents the $k$ th eigenvector.

We apply captured PCs to rebuild the original time series, and the corresponding reconstructed components (RCs) are received:

$$
R_{k}(t)=\frac{1}{M_{t}} \sum_{K \in k} \sum_{j=L_{t}}^{U_{t}} H_{k}(t+j-1) \beta_{k}(j),
$$

where $R_{k}(t)$ is the RCs for time series, $k$ represents the set of indices, $M_{t}$ denotes the normalization factor, $L_{t}$ and $U_{t}$ depict the lower and upper bounds of summation, respectively.

The determination of the window length $(L)$ plays a vital role in the final result of SSA. With the unique values of $L$, the financial cycles will take on different performances. Therefore, an appropriate $L$ needs to be set. There is no fixed method or procedure in the selection of $L$, and it is often determined depending on specific practical problems. According to 
Vautard et al. (1992), when $L$ was within $(N / 5, N)$ interval ( $N$ refers to the entire length of the time series), periodic extraction would be more successful. Following this treatment, a possible optimal $L$ is $N / 5$. Then, as noted by Elsner (2002), it was a general rule of thumb when $L$ was $N / 2$. Furthermore, a window-closing procedure was proposed by Iacobucci (2005). In this study, the window-closing procedure is performed to determine the optimal window length $L$.

\subsection{Econometric analysis}

This paper adopts several econometric methods, including the VAR model, TVP-VAR model and the Granger causality test, to investigate the comovement and relationship between the financial and literature variables. First, the vector autoregressive (VAR) model is introduced. The VAR model was first proposed by Sims (1980). It has been widely used to study the correlation among various variables in the macroeconomic field. Regarding a VAR $(\eta)$ model with $g(g=1,2, \ldots, G)$ samples, the general expression is:

$$
\begin{aligned}
& y_{g}=F_{1}+\sum_{i=1}^{\eta} A_{i} y_{g-i}+\sum_{i=1}^{\eta} A^{\prime}{ }_{i} x_{g-i}+\varepsilon_{1 g} ; \\
& x_{g}=F_{2}+\sum_{i=1}^{\eta} B_{i} y_{g-i}+\sum_{i=1}^{\eta} B_{i}^{\prime} x_{g-i}+\varepsilon_{2 g},
\end{aligned}
$$

where $y_{g}$ denotes the financial variables, $x_{g}$ depicts the literature variables, $F$ is the constant, $A$ and $B$ represent different coefficients, $\eta$ is the lag length and $\varepsilon$ shows the disturbance vector in this paper.

As for the optimal lag length of the VAR model, we usually judge it according to the principle of Akaike Info Criterion (AIC), Schwarz Criterion (SC) and Hannan-Quinn (HQ) information criteria (Nielsen, 2001). Once the VAR model is constructed, we need to test its stability. If the model is stable, then we can use the impulse-response functions to detect the dynamic relationship among variables under the VAR model's framework.

The classical VAR model assumes that the observed variables have the same variance and coefficients. A new VAR algorithm was raised and developed by Primiceri (2005), namely the time-varying parameter vector autoregression (TVP-VAR) model. It allows for time variation both in the coefficients and the variance-covariance matrix (Wen et al., 2019). The measurement formula of the TVP-VAR model is given by

$$
y_{t}=\alpha_{t}+\beta_{1, t} y_{t-1}+\cdots+\beta_{\delta, t} y_{t-\delta}+\lambda_{t}^{-1} \sum_{t} \zeta_{t}
$$

where $y_{t}$ refers to a $k \times 1$ vector of given financial and literature variables, $\beta_{i, t}$ is the $k \times k$ matrix for time-varying coefficients and $\lambda_{t}$ denotes a lower triangular matrix that estimates the synchronization relationship among the multiple variables, shown as:

$$
\lambda_{t}=\left(\begin{array}{cccc}
1 & 0 & \cdots & 0 \\
a_{21, t} & \ddots & \ddots & \vdots \\
\vdots & \ddots & \ddots & 0 \\
a_{k 1, t} & \cdots & a_{k k-1, t} & 1
\end{array}\right) .
$$


Accordingly, $\sum_{t}$ indicates the diagonal matrix that reflects the stochastic volatilities

$$
\sum_{t}=\left(\begin{array}{cccc}
\vartheta_{1, t} & 0 & \ldots & 0 \\
0 & \ddots & \ddots & \vdots \\
\vdots & \ddots & \ddots & 0 \\
0 & \ldots & 0 & \vartheta_{k, t}
\end{array}\right) .
$$

Besides, the TVP-VAR model is expressed as:

$$
y_{t}=X_{t} \partial_{t}+\lambda_{t}^{-1} \sum_{t} \zeta_{t}, t=\delta+1, \cdots, n
$$

where $\partial_{t}, \lambda_{t}$ and $\sum$ are all time-varying parameters.

Suppose that theret is a stacked vector $a_{t}$ in the lower triangular elements with respect to $\lambda_{t}$, and $l_{t}=\left(l_{1 t}, l_{2 t}, \cdots, l_{k t}\right)^{\prime}$ in terms of $l_{j t}=\log \vartheta_{j t}^{2}$ for $j=1,2, \ldots, k$ and for $t=\delta+1, \ldots, n$. As a result, these parameters follow the random walk process as follows:

$$
\begin{aligned}
& \partial_{t+1}=\partial_{t}+\tau_{\partial t} \\
& a_{t+1}=a_{t}+\tau_{a t} \\
& l_{t+1}=l_{t}+\tau_{l t} \\
& \partial_{\delta+1} \sim N\left(\tau_{\partial_{0}}, \sum_{\partial_{0}}\right) \\
& a_{\delta+1} \sim N\left(\tau_{a_{0}}, \sum_{a_{0}}\right) \\
& l_{\delta+1} \sim N\left(\tau_{l_{0}}, \sum_{l_{0}}\right)
\end{aligned}
$$

Then, the block diagonal variance-covariance matrix is constructed as follows:

$$
\left(\begin{array}{l}
\zeta_{t} \\
\tau_{\partial t} \\
\tau_{a t} \\
\tau_{l t}
\end{array}\right) \sim N\left(0,\left(\begin{array}{cccc}
I & 0 & 0 & 0 \\
0 & \sum_{\partial} & 0 & 0 \\
0 & 0 & \sum_{a} & 0 \\
0 & 0 & 0 & \sum_{l}
\end{array}\right)\right) .
$$

An important purpose of this study is to investigate the one-to-one causal nexus between the financial variables and literature ones, and thus the technique of Granger causality test is employed (Granger, 1969). The setting of optimal lag length in the Granger causality test is consistent with that in the VAR model. It is important to highlight that the Granger causality test results only state a kind of prediction and do not equal actual causality in the usual sense. As a test approach, the null hypothesis of the Granger causality test is usually no causality. Take the test from financial variables to literature ones as an example, the financial variables $y_{g}$ do not Granger cause literature variables $x_{g}$. If we reject the null hypothesis, then this means that there are Granger causalities from the financial variables to literature ones. 
Therefore, the present financial situation helps to predict the development of future literature. There are four cases of the results of Granger causality test: (1) unidirectional Granger causality from financial variables to literature ones; (2) unidirectional Granger causality from literature variables to financial ones; (3) bidirectional Granger causality between financial variables and literature ones; (4) no Granger causality. These situations will be displayed in this paper.

\section{Results}

This section presents the empirical results and some discussions about our study. In the beginning, we make a descriptive analysis of bibliometric results. Then, the captured and identified financial cycles in the economy and in economic research are given in Subsection 2.2, and Subsection 2.3 clarifies the links between financial activities and the development in financial research. Finally, some discussions are illustrated in Subsection 2.4.

\subsection{Bibliometric results}

Figure 2 presents a stacked area chart using the statistical data of literature variables for journal articles in terms of CNKI from 1979 to 2019. The stacked area chart shows the trend of each line over time, which can reflect the development of the same series at different times. Also, it can highlight the area occupied by each series and help us seize the overall trend. It can be seen that the "total", "bank", "market" and "finance" take a larger occupancy ratio. The most interesting aspect is that almost all series exhibit the same pattern of volatility along with the movement. From 1979 to 1993, all lines display an upward trend in the linear generation, relatively flat. A steep rise took place in 1993, especially for "cycle". In a similar vein, a small swing happened in 1997, although the intensity is weaker than in 1993. Since approximately 1999, all series once again step into a period of steady growth until about 2007. In 2007, a nearly violent and rapid wave was performed for all series and end with 2009. Last but not least, from about 2009 until now, an overall downward trend emerges despite a slight up in about 2012 .

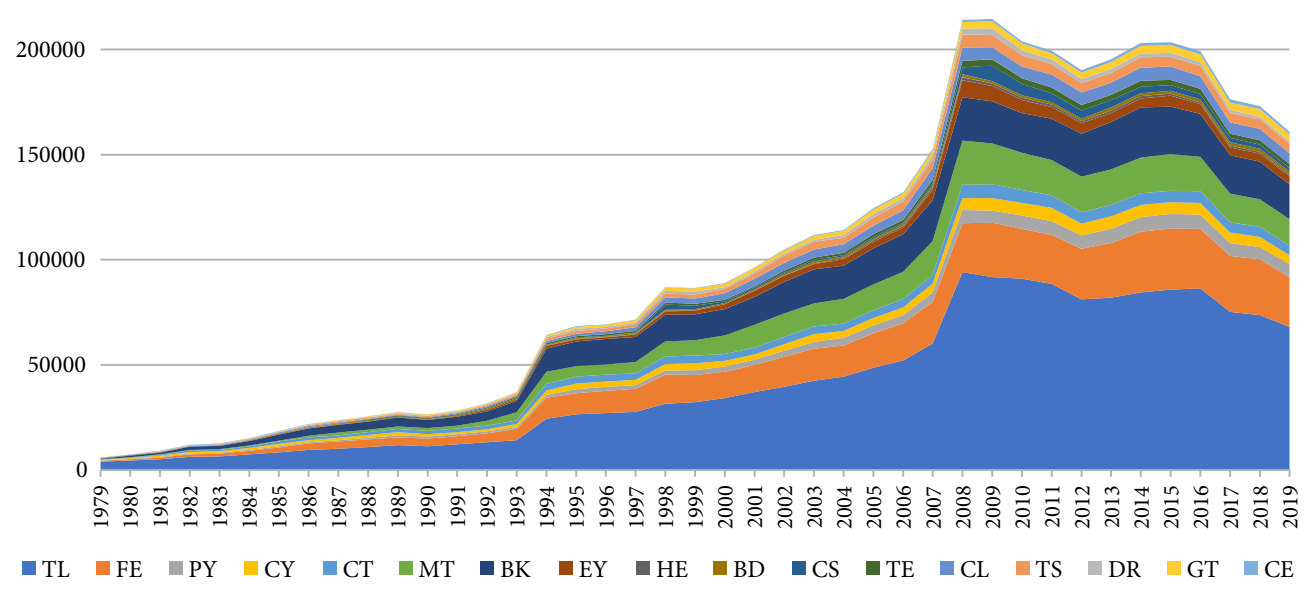

Figure 2. The trend ratio of literature variables from 1979 to 2019 (source: authors' calculation) 
Next, additional insights are provided by detecting their respective trends, namely the annual fluctuations in the number of publications from 1979 to 2019. In Figure 3 (a), we portray the distribution pattern of 16 lines. A closer look at the overall layout, we can divide the figure into two areas: the "finance", "market" and "bank" terms; the other is the remaining 13 series. The top half of the figure illustrates that the "finance", "market" and "bank" are always at a higher level, for almost the entire period. These three lines are roughly consistent in the trend of evolution. But there are still some differences in the term of their specific numerical values. The "market" line is nearly always lower than "finance" and "bank", in the third position from beginning to end. When closely looking at the "finance" and "bank" series, during about from 1979 to 2007, they are in an intertwined state, whether it is a trend or value. Later, an apparent distance appears between them in the chart. The "finance" suddenly goes beyond the "market" at the point in 2007, while their waves and fluctuations are still almost parallel. Besides, in contrast to the other two lines, the "market" does not show a significant increase in 2012, but a slight decline. Afterward, the rest of the 13 series are manifested in the bottom half of the chart. Since their values are at a lower level compared to the top three sequences, and their fluctuations and trends are not well represented in Figure 3a. To this end, these 13 sequences are separated for further observation and analysis, as shown in Figure $3 \mathrm{~b}$. Besides the collective characteristics observed above, these series perform even more volatile, and several distinguishing features immediately catch the eye. A few lines experience relatively large falloff around 1998, in particular for "crisis" series. Only the "crisis" maintains almost stagnant growth between 2000 and about 2007. However, the number of publications jumped from 750 to 7500 from 2007 to 2008, followed by a steep descent. For another, some series do not show large ups and downs, but rather show a relatively gentle growth trend, the most typical of which is the "bond". It does not appear an obvious shock around 1993, 1997 or 2007 like other series. Overall, nearly all sequences peak approximately 2008, after which they slowly drop.

The above intuitive analysis has preliminarily shed light on that there is an association between financial cycles in the real economy and in the economic literature. Whereas, the qualitative descriptive analysis has some deviations, although the ultimate results seem to be reasonable. Therefore, it is necessary to conduct a rigorous quantitative experiment for objectively validating the speculation of this paper. A suite of econometric approaches is adopted and carried out in this study. Before this, in the following, we identify and capture financial cycles in the economy and literature.

\subsection{Financial cycles in the economy and in economic research}

Based on selected variables and samples, we use the SSA to isolate and extract financial cycles in the real economy and financial research of China. After standardization and preprocessing with HP filter, the reconstructed dominant periodicity is easily characterized and captured. According to Drehmann et al. (2012), the duration between two consecutive peaks was defined as a financial cycle. The univariate cycles of variables, both in reality and in the literature, are revealed.

On the one hand, Figure 4 illustrates financial cycles in China for credit-to-GDP ratio, credit to the private non-financial sector, house price index, bond prices, equity prices and pur- 


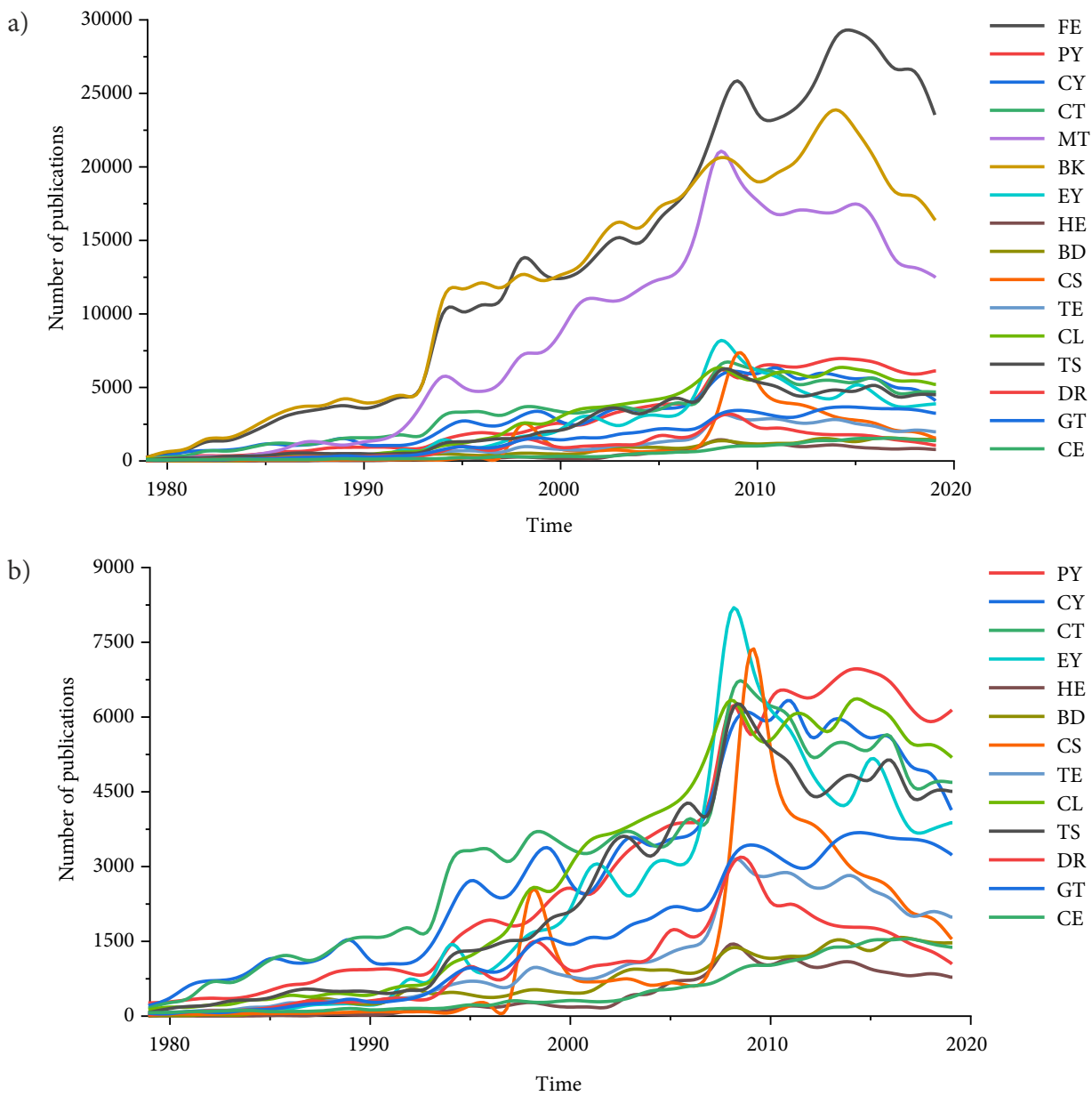

Figure 3. Chronological distribution of journal articles from 1979 to 2019 (source: authors' calculation)

chasing managers' index. We can see that although the outcomes of the HP filter also show a certain periodicity, the length of the cycle cannot be strictly judged as a result of too much noise in series. In comparison, the cyclical series obtained by SSA treatment are smoother and more regular. In this way, periodic characteristics can be identified. On the whole, the average lengths of cycles of credit-to-GDP ratio, credit to the private non-financial sector, house price index, bond prices, equity prices and PMI are 5.7 years, 4.2 years, 3.1 years, 3.4 years, 8.2 years and 3.5 years, respectively. As a result, the average financial cycle in China is approximately 4.7 years. The average financial cycle duration found in this study is in line with the finding of Škare and Porada-Rochon (2019) that cycles last, on average, five years in transitional economies. Compared to other indicators, the cycles of credit-to-GDP ratio and bond prices are more pronounced, with larger amplitude and slope. As far as credit to the private non-financial sector (see Figure $4 \mathrm{~b}$ ) and PMI (see Figure $4 \mathrm{f}$ ) are concerned, both of their later cycles become less distinct and show long-memory properties. Interestingly, 
the house price index performs the opposite trend, and the periodic features become more prominent and intense. Also, the peaks and troughs of these six indicators are consistent after the 2008 shock, which shows that they have common contraction characteristics and expansion. Meanwhile, judging from the changes in amplitude of fluctuations, the house price index has increased significantly since 2008 , which has been primarily related to the rapid growth rate of housing prices in China.

On the other hand, financial cycles in economic research are also depicted in this paper. Figure 5 shows the selected financial cycles in financial research. The average length of cycle of "total" is 7.2 years, "bond" is 5.7 years, "capital" is 3.3 years, "credit" is 4.6 years, "cycle" is 7.7 years and with an average cycle of 3.4 years of "house". The overall average cycle of these selected six terms is around 5.3 years, slightly higher than that in the economy. From 1979 to 2019 , there are two unique types of periodic intensity variations, as shown in the chart.

a)

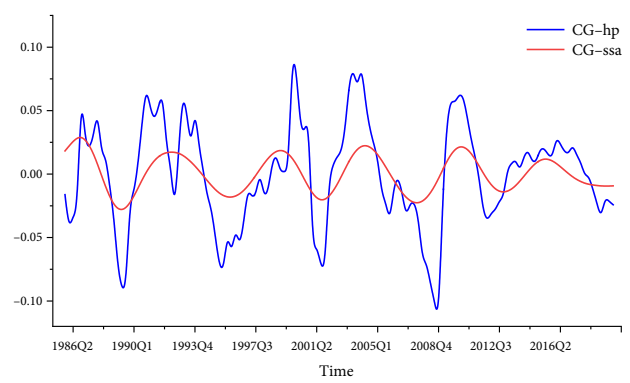

c)

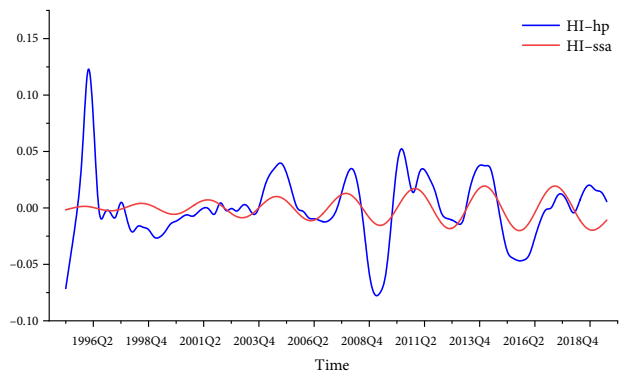

e)

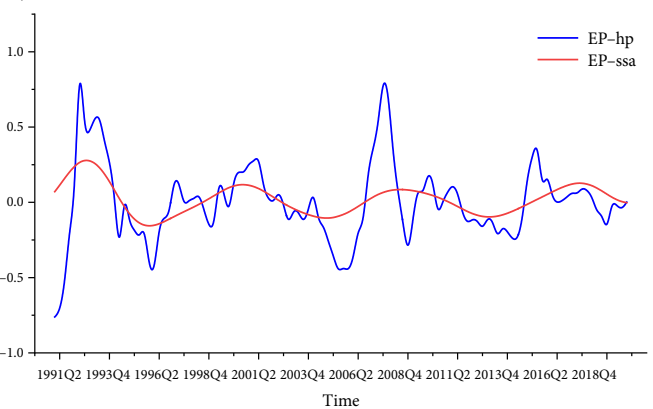

b)

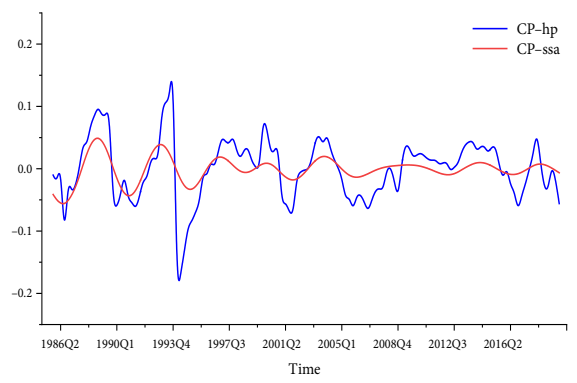

d)

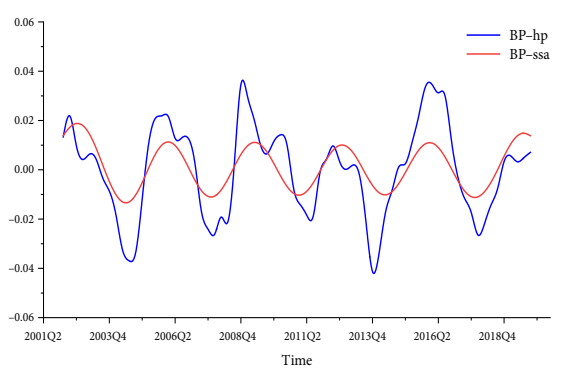

f)

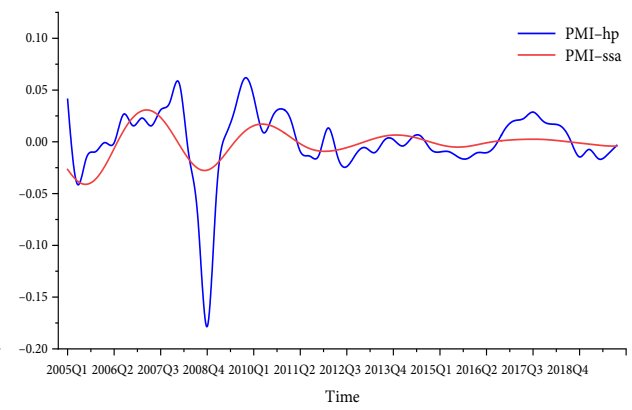

Figure 4. Financial cycles in China for $C G, C P, H I, B P, E P$ and $P M I$ (source: authors' calculation) 
a)

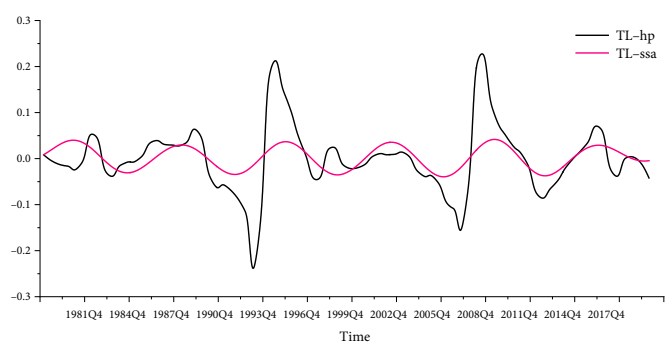

c)

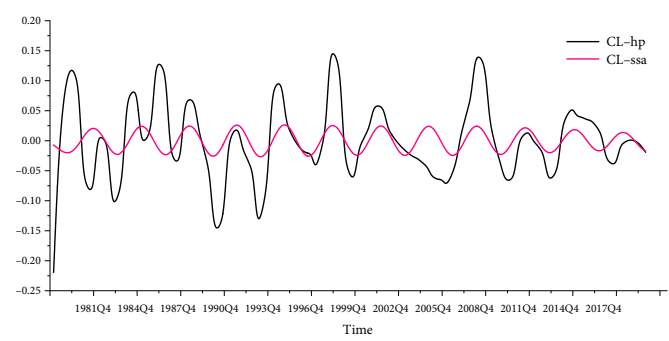

e)

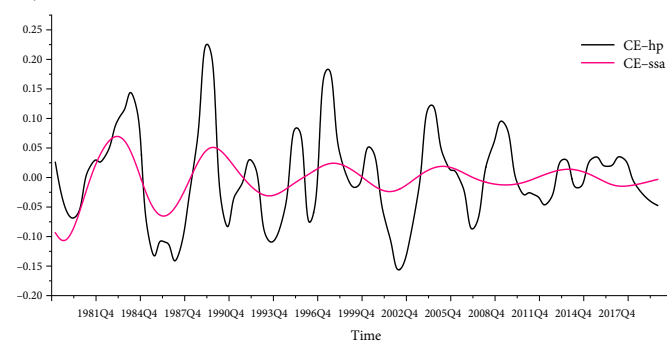

b)

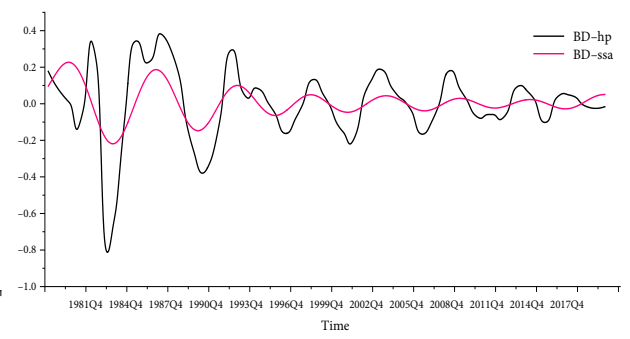

d)

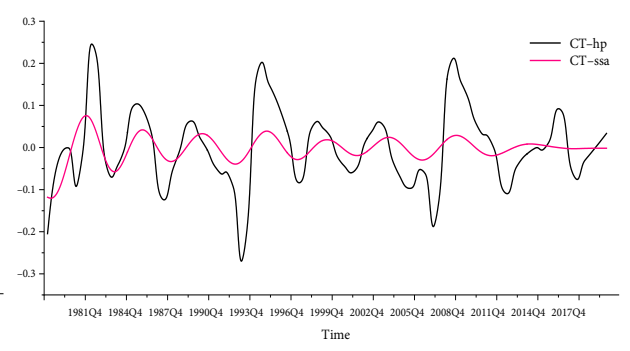

f)

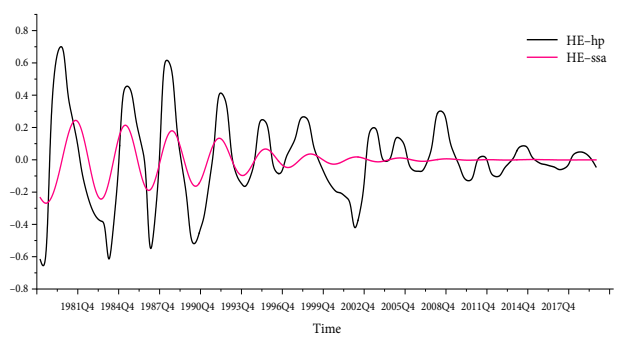

Figure 5. Selected financial cycles in financial research of China (source: authors' calculation)

One is that the intensity gradually weakens, such as "bond" and "house" series. The other is almost uniformly fluctuating from beginning to end, whether it is amplitude or slope, such as "total" and "capital". There is no such situation about financial cycles in the literature, in which a significant upswing in volatility levels is displayed, as illustrated in Figure 4c.

\subsection{The comovement between financial cycles in the economy and in the literature}

In this subsection, we present the findings concerning the connection between financial variables and bibliometric ones using econometric methods described in Subsection 1.4, which begins with the execution of the unit root test for all variables. Regarding the time series data in the econometric model, the stationary property must be satisfied. Otherwise, it will cause the occurrence of spurious regression. Therefore, the unit root test technique is usually applied to tackle this question. There are many standard methods for unit root tests. In this study, we use the DF-GLS (Dickey-Fuller with Generalized Least Squares) test to achieve this goal (Elliott et al., 1996). A note on the confidence level is that the $5 \%$ benchmark is 
used for all the tests in this study. As a result, we show a summary of the unit root test for all variables in Table 3. The results show that almost all variables expressed at a 5\% level are non-stationary, except for house price index and PMI. We use the stationary financial and bibliometric cycles obtained via the above HP filter to implement the subsequent experiment. Once the stationary cyclical fluctuation data are acquired, the next step is to establish a VAR framework. The bivariate VAR model is employed for our analysis because of the nonuniform time frames for all the variables.

Under the architecture of the VAR model, Table 4 reports the Granger causality tests for the bibliometric and financial variables. Here, we distinguish among the Granger causality of financial to bibliometric variables, reverse Granger causality in the direction towards financial ones and instantaneous Granger causality (Granger, 1980). In Table 4, the p-values reveal all test results between the financial and bibliometric variables. If the p-value is lower than $5 \%$, then we reject the null hypothesis, there exists a Granger causality between them. Under each financial variable, two columns of data are exhibited. They represent the results of the Granger causality test in different directions. The left is financial variables to bibliometric ones, and the right is bibliometric variables to financial ones.

Table 3. Unit root results (source: authors' calculation)

\begin{tabular}{|c|c|c|c|c|}
\hline Group & Variables & DF-GLS tau test statistic & $5 \%$ critical value & Results \\
\hline \multirow{6}{*}{ Financial } & $C G$ & -2.487 & -2.976 & Non-stationary \\
\hline & $C P$ & -1.140 & -2.976 & Non-stationary \\
\hline & $H I$ & -5.684 & -3.026 & Stationary \\
\hline & $B P$ & -2.572 & -3.093 & Non-stationary \\
\hline & $E P$ & -1.325 & -2.999 & Non-stationary \\
\hline & $P M I$ & -3.462 & -3.140 & Stationary \\
\hline \multirow{17}{*}{ Bibliometric } & $T L$ & -0.686 & -2.953 & Non-stationary \\
\hline & $B K$ & -0.126 & -2.953 & Non-stationary \\
\hline & $B D$ & -1.065 & -2.953 & Non-stationary \\
\hline & $C L$ & -0.016 & -2.953 & Non-stationary \\
\hline & $C T$ & -0.383 & -2.953 & Non-stationary \\
\hline & $C S$ & -2.422 & -2.953 & Non-stationary \\
\hline & $C Y$ & -0.741 & -2.953 & Non-stationary \\
\hline & $C E$ & -2.289 & -2.953 & Non-stationary \\
\hline & $D R$ & -0.336 & -2.953 & Non-stationary \\
\hline & $E Y$ & -1.067 & -2.953 & Non-stationary \\
\hline & $F E$ & 0.010 & -2.953 & Non-stationary \\
\hline & $G T$ & -1.563 & -2.953 & Non-stationary \\
\hline & $M T$ & -0.312 & -2.953 & Non-stationary \\
\hline & $P Y$ & -1.512 & -2.953 & Non-stationary \\
\hline & $H E$ & -1.191 & -2.953 & Non-stationary \\
\hline & $T E$ & -0.914 & -2.953 & Non-stationary \\
\hline & $T S$ & -0.507 & -2.953 & Non-stationary \\
\hline
\end{tabular}

Note: only the results of 1 lag are given. 


\begin{tabular}{|c|c|c|c|c|c|c|c|c|c|c|c|c|c|c|c|c|c|c|}
\hline \multirow{2}{*}{$\sum_{\Omega}$} & 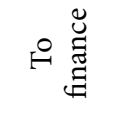 & 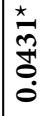 & $\stackrel{\infty}{\exists}$ & 능 & 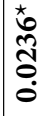 & 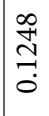 & 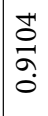 & ふু & 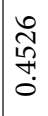 & $\begin{array}{c}0 \\
\stackrel{7}{7} \\
\stackrel{\sim}{0}\end{array}$ & \begin{tabular}{l}
$\stackrel{n}{0}$ \\
$\cdots$ \\
\hdashline \\
0
\end{tabular} & 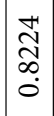 & \begin{tabular}{|l|}
$\infty$ \\
10 \\
\multirow{1}{*}{} \\
0 \\
0
\end{tabular} & $\begin{array}{l}0 \\
0 \\
0 \\
0 \\
0 \\
0\end{array}$ & 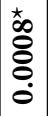 & 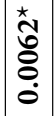 & $\begin{array}{l}\hbar \\
\cdots \\
m \\
0 \\
0 \\
0 \\
0\end{array}$ & 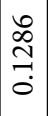 \\
\hline & 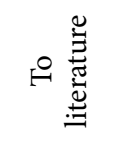 & م. & $\begin{array}{l}\hat{n} \\
\infty \\
0 \\
0\end{array}$ & $\begin{array}{l}\infty \\
\infty \\
\infty \\
\infty \\
0 \\
0\end{array}$ & 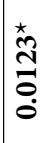 & 苫 & $\begin{array}{l}\infty \\
10 \\
10 \\
0 \\
0\end{array}$ & 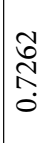 & $\begin{array}{l}0 \\
2 \\
2 \\
0 \\
0 \\
0\end{array}$ & $\begin{array}{l}0 \\
\alpha \\
\hat{\omega} \\
\infty \\
0\end{array}$ & $\begin{array}{c}8 \\
0 \\
0 \\
0 \\
0\end{array}$ & 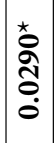 & $\mid \begin{array}{c}2 \\
2 \\
10 \\
\infty \\
0\end{array}$ & $\begin{array}{l}10 \\
20 \\
+4 \\
-1 \\
0\end{array}$ & 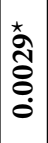 & $\mid \begin{array}{l}0 \\
\stackrel{2}{o} \\
\stackrel{0}{0}\end{array}$ & 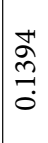 & $\begin{array}{l}\frac{2}{2} \\
\stackrel{+}{N} \\
0\end{array}$ \\
\hline \multirow{2}{*}{ 로 } & 을 & $\mid$\begin{tabular}{l}
$x$ \\
$\infty$ \\
\hdashline \\
0 \\
0 \\
0
\end{tabular} & 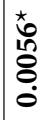 & స్ & $\frac{9}{2}$ & 茴 & 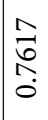 & 离 & 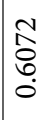 & 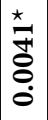 & $\begin{array}{c}\hat{N} \\
\hat{N} \\
\cdots \\
0\end{array}$ & 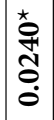 & 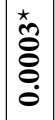 & 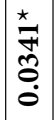 & ثิ̀ & $\mid \begin{array}{c}\underset{N}{N} \\
\infty \\
\dot{0} \\
\dot{0}\end{array}$ & 苍 & 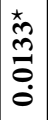 \\
\hline & 을 & 离 & $\begin{array}{l}0 \\
\hat{n} \\
\hat{n} \\
0\end{array}$ & 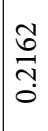 & 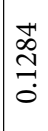 & 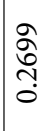 & $\begin{array}{l}\infty \\
\hat{0} \\
0 \\
1 \\
0\end{array}$ & 우 & 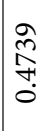 & 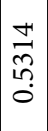 & 齐 & $\begin{array}{l}8 \\
\vdots \\
0 \\
0 \\
0\end{array}$ & 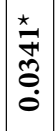 & 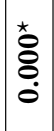 & $\begin{array}{l}\vec{a} \\
\tilde{\sigma} \\
\ddot{0}\end{array}$ & $\mid \begin{array}{l}\vec{n} \\
\hat{T} \\
\stackrel{0}{0}\end{array}$ & \begin{tabular}{l}
\multirow{1}{n}{} \\
$\stackrel{n}{n}$ \\
0 \\
0 \\
0 \\
0
\end{tabular} & $\begin{array}{l}10 \\
0 \\
0 \\
0 \\
0\end{array}$ \\
\hline \multirow{2}{*}{$\vec{n}$} & $\circ \underset{\mathscr{\Xi}}{\mathscr{\Xi}}$ & $\begin{array}{l}0 \\
\stackrel{2}{0} \\
\stackrel{0}{0}\end{array}$ & $\begin{array}{l}+ \\
+ \\
\infty \\
+ \\
0\end{array}$ & $\begin{array}{l}n \\
\tilde{0} \\
0 \\
0 \\
0\end{array}$ & 茼 & 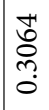 & ڤ్రి & $\begin{array}{l}\hat{\sigma} \\
\hat{n} \\
\hat{n} \\
0\end{array}$ & 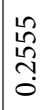 & 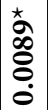 & 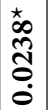 & 点 & 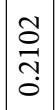 & 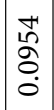 & $\begin{array}{l}\stackrel{0}{7} \\
\underset{+}{0} \\
\end{array}$ & 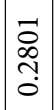 & 굴 & $\begin{array}{l}0 \\
\text { N } \\
\\
0 \\
0\end{array}$ \\
\hline & 의 & 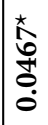 & 芯 & ‡ิ & 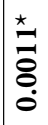 & $\begin{array}{l}0 \\
1 \\
n \\
n \\
0\end{array}$ & ڤె & $\begin{array}{c}0 \\
0 \\
0 \\
0 \\
0\end{array}$ & $\begin{array}{c}0 \\
\infty \\
0 \\
10 \\
0\end{array}$ & 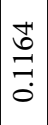 & $\begin{array}{l}\tilde{n} \\
\hat{b} \\
+ \\
0\end{array}$ & 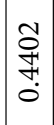 & $\mid \begin{array}{c}\hat{n} \\
\stackrel{2}{0} \\
0 \\
0\end{array}$ & 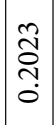 & 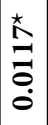 & 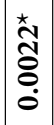 & 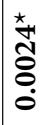 & \begin{tabular}{l}
0 \\
2 \\
\multirow{1}{*}{} \\
0
\end{tabular} \\
\hline \multirow{2}{*}{ 圼 } & $\ominus \underset{\breve{G}}{\stackrel{\Xi}{\Xi}}$ & $\begin{array}{l}0 \\
0 \\
0 \\
+1 \\
0\end{array}$ & $\begin{array}{l}\vec{\infty} \\
\vdots \\
\vdots \\
0\end{array}$ & 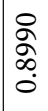 & $\begin{array}{l}\text { t. } \\
\text { o̊ } \\
8 \\
0 \\
0\end{array}$ & 高 & $\begin{array}{l}n= \\
0 \\
10 \\
0 \\
0\end{array}$ & $\begin{array}{l}1 \\
0 \\
1 \\
\infty \\
0 \\
0\end{array}$ & $\begin{array}{l}\overrightarrow{0} \\
0 \\
\infty \\
0\end{array}$ & $\begin{array}{l}1 \\
\infty \\
\infty \\
0 \\
0 \\
0\end{array}$ & $\begin{array}{l}n \\
\hat{N} \\
\hat{O} \\
0 \\
0\end{array}$ & $\begin{array}{l}8 \\
\stackrel{0}{1} \\
m \\
0 \\
\end{array}$ & 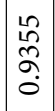 & 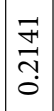 & $\begin{array}{l}0 \\
+ \\
0 \\
0 \\
0\end{array}$ & 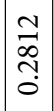 & 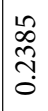 & $\frac{2}{2}$ \\
\hline & 의 & 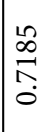 & 尽 & 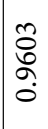 & ঐે & 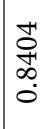 & चू & 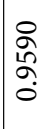 & 송 & $\mid \begin{array}{l}2 \\
\sigma \\
\infty \\
0\end{array}$ & $\mid \begin{array}{l}0 \\
0 \\
\infty \\
\infty \\
0\end{array}$ & \begin{tabular}{|l|}
1 \\
0 \\
0 \\
1 \\
0 \\
0
\end{tabular} & $\mid \begin{array}{l}n \\
\tilde{2} \\
\hat{N} \\
0\end{array}$ & 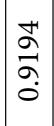 & 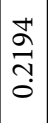 & \begin{tabular}{|l|}
0 \\
0 \\
0 \\
+ \\
0 \\
0
\end{tabular} & \begin{tabular}{l}
0 \\
\multirow{2}{\alpha}{} \\
$\vdots$ \\
0
\end{tabular} & $\begin{array}{l}0 \\
\vdots \\
\vdots \\
\vdots \\
0\end{array}$ \\
\hline \multirow{2}{*}{ తి } & 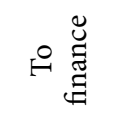 & 离 & 淢 & ڤึ & 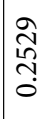 & $\stackrel{10}{\tilde{N}}$ & $\begin{array}{l}n \\
\infty \\
\infty \\
0 \\
0\end{array}$ & $\begin{array}{l}\infty \\
\infty \\
\vdots \\
\vdots \\
0\end{array}$ & กี & 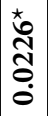 & $\begin{array}{c}0 \\
\stackrel{1}{1} \\
0 \\
\end{array}$ & 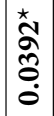 & 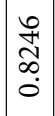 & $\begin{array}{l}1 \\
\hat{R} \\
6 \\
1 \\
0 \\
0\end{array}$ & 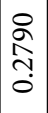 & 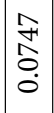 & ڤ̊̊ & 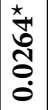 \\
\hline & 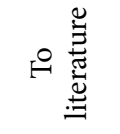 & 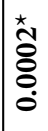 & 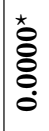 & $\begin{array}{l}0 \\
0 \\
0 \\
0 \\
0\end{array}$ & $\begin{array}{l}0 \\
8 \\
1 \\
0 \\
0\end{array}$ & 芯 & $\begin{array}{l}0 \\
L \\
\stackrel{1}{1} \\
1 \\
0\end{array}$ & 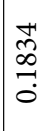 & 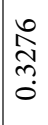 & 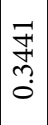 & $\begin{array}{l}\text { to } \\
0 \\
0 \\
0 \\
0 \\
0 \\
0\end{array}$ & 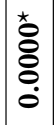 & 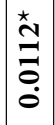 & 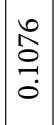 & $\begin{array}{l}0 \\
\mathscr{0} \\
0 \\
0 \\
0\end{array}$ & 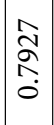 & 冬 & 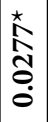 \\
\hline \multirow{2}{*}{ ن } & 으류 & 范 & \begin{tabular}{l}
$\infty$ \\
$m$ \\
\multirow{2}{*}{} \\
0
\end{tabular} & $\begin{array}{l}8 \\
8 \\
2 \\
0 \\
0\end{array}$ & $\begin{array}{l}+1 \\
\stackrel{1}{2} \\
\vdots \\
0\end{array}$ & 号 & 态 & $\underset{N}{N}$ & 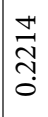 & 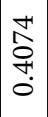 & $\begin{array}{l}\overrightarrow{\hat{O}} \\
0 \\
0 \\
0\end{array}$ & 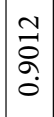 & 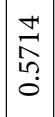 & $\begin{array}{l}0 \\
8 \\
6 \\
0 \\
0\end{array}$ & $\begin{array}{l}\vec{b} \\
0 \\
0 \\
0\end{array}$ & $\mid \begin{array}{c}\hat{\tilde{m}} \\
\hat{\tilde{O}} \\
\tilde{0} \\
\end{array}$ & $\begin{array}{l}0 \\
10 \\
\\
0 \\
0\end{array}$ & $\begin{array}{l}0 \\
0 \\
0 \\
0 \\
0\end{array}$ \\
\hline & 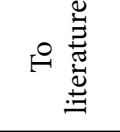 & $\begin{array}{l}0 \\
8 \\
0 \\
0 \\
0\end{array}$ & $\begin{array}{l}\infty \\
\vdots \\
\vdots \\
\vdots \\
0\end{array}$ & 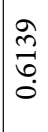 & 兽 & $\begin{array}{l}0 \\
0 \\
\mathbb{N} \\
0 \\
0\end{array}$ & ત્స & 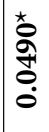 & 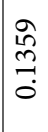 & 㐫 & 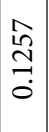 & $\begin{array}{l}\overrightarrow{\widehat{\alpha}} \\
\bar{\sigma} \\
0\end{array}$ & $\begin{array}{l}\stackrel{2}{+} \\
\underset{+}{+} \\
\dot{0}\end{array}$ & \begin{tabular}{l|}
0 \\
$\infty$ \\
$\infty$ \\
0 \\
0 \\
0
\end{tabular} & $\begin{array}{l}0 \\
0 \\
0 \\
0 \\
0\end{array}$ & $\mid$ & $\begin{array}{l}n \\
\hat{N} \\
\hat{N} \\
0\end{array}$ & 先 \\
\hline$\frac{\mathscr{0}}{0.0}$ & 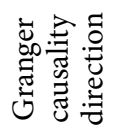 & $\forall$ & $\frac{\mathbb{N}}{\infty}$ & $\stackrel{\oplus}{\curvearrowright}$ & $\overrightarrow{0}$ & 5 & $\tilde{c}$ & $\overrightarrow{\mathrm{u}}$ & ST & 兄 & 至 & 空 & $\overleftarrow{\circlearrowleft}$ & $\stackrel{5}{\Sigma}$ & $\vec{a}$ & 空 & 国 & $\mathscr{H}$ \\
\hline $\begin{array}{l}O \\
Z\end{array}$ & & - & $N$ & $m$ & $H$ & in & 6 & $\Lambda$ & $\infty$ & $a$ & 음 & $\exists$ & $\approx$ & 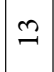 & $\Xi$ & 10 & $\stackrel{0}{-1}$ & $\triangleq$ \\
\hline
\end{tabular}


To be specific, let us detect whether financial cycles produce scientific literature. The outcomes of Granger causality test from financial variables to bibliometric ones state that the cyclical fluctuations of credit-to-GDP ratio Granger cause bibliometric series on "currency" and "house"; the cyclical fluctuations of credit to private non-financial sector Granger cause "credit", "equity" and "government"; the cyclical fluctuations of house price index do not Granger cause any bibliometric series; the cyclical fluctuations of bond prices Granger cause the most bibliometric data, i.e., "total", "bank", "policy", "house" and "trade"; the cyclical fluctuations of equity prices Granger cause only one variable, namely "equity"; in the same light, the cyclical fluctuations of PMI Granger cause only fluctuations in the literature associated with the term "finance".

We also give the results of the reverse Granger causality test in Table 4 . We can investigate this finding for the cyclical fluctuations of credit-to-GDP ratio Granger and "crisis"; credit to private non-financial sector and "bond", "dollar"; house price index and "cycle"; bond prices and "dollar", "equity"; equity prices and "bank", "credit", "currency", "dollar", "finance", "policy" and "trustworthiness"; PMI and "total", "house" and "trade".

Besides, we discover some instantaneous Granger causalities for the following cyclical fluctuations: credit to the private non-financial sector and "total", "bank", "finance" and "trustworthiness"; bond prices and "cycle"; equity prices and "total", "government", "market" and "trade"; PMI and "capital", "policy". In conclusion, 12 incidents of Granger causalities from financial variables to bibliometric ones, 16 events of reverse Granger causalities, and 11 matters of instantaneous Granger causalities are found in this study.

According to the above Granger causalities, the impulse-response functions enable us to investigate how a variable reacts to other ones along with their movements based on the VAR estimation. The stability test of the VAR model needs to be performed first. Only in this way can we execute the next simulations. As a result, Figure 6 offers the selected impulse-response functions because of space limitations. It is apparent that a positive impulse from equity prices brings about a positive reaction of the literature series on "equity" and "government" terms. Similarly, PMI results in a positive reaction of "cycle". Whereas credit-to-GDP ratio, "trustworthiness" and "total" lead to an adverse reaction of the series on "currency", equity prices, and PMI, respectively. Figure 6 purely displays a part of impulse-response functions for Granger causality results. Because of the similar characteristics and patterns, they are chosen and gathered.

Moreover, we examine the links and relationship between financial and literature variables in a time-varying framework. According to Granger causality results above, we take the $P M I$, "finance" and "capital" three variables as a representative to reveal this phenomenon. As a result, a trivariate TVP-VAR model is established to explore the time-varying impact among the variables in this study.

First, we set the optimal lag length as one according to the AIC rule. Following Nakajima (2011) approach, we use the Markov chain Monte Carlo (MCMC) method to estimate the time-varying parameters. Table 5 reports the estimation results of the selected parameters of the TVP-VAR model, and parameters from left to right are in order of the posterior means, standard deviations, upper and lower 95\% confidence intervals, Geweke convergence diagnostics and the inefficiency factors. Clearly, the posterior means are within the confines of the $95 \%$ confidence intervals, and the output of Geweke shows that the null hypothesis, namely 

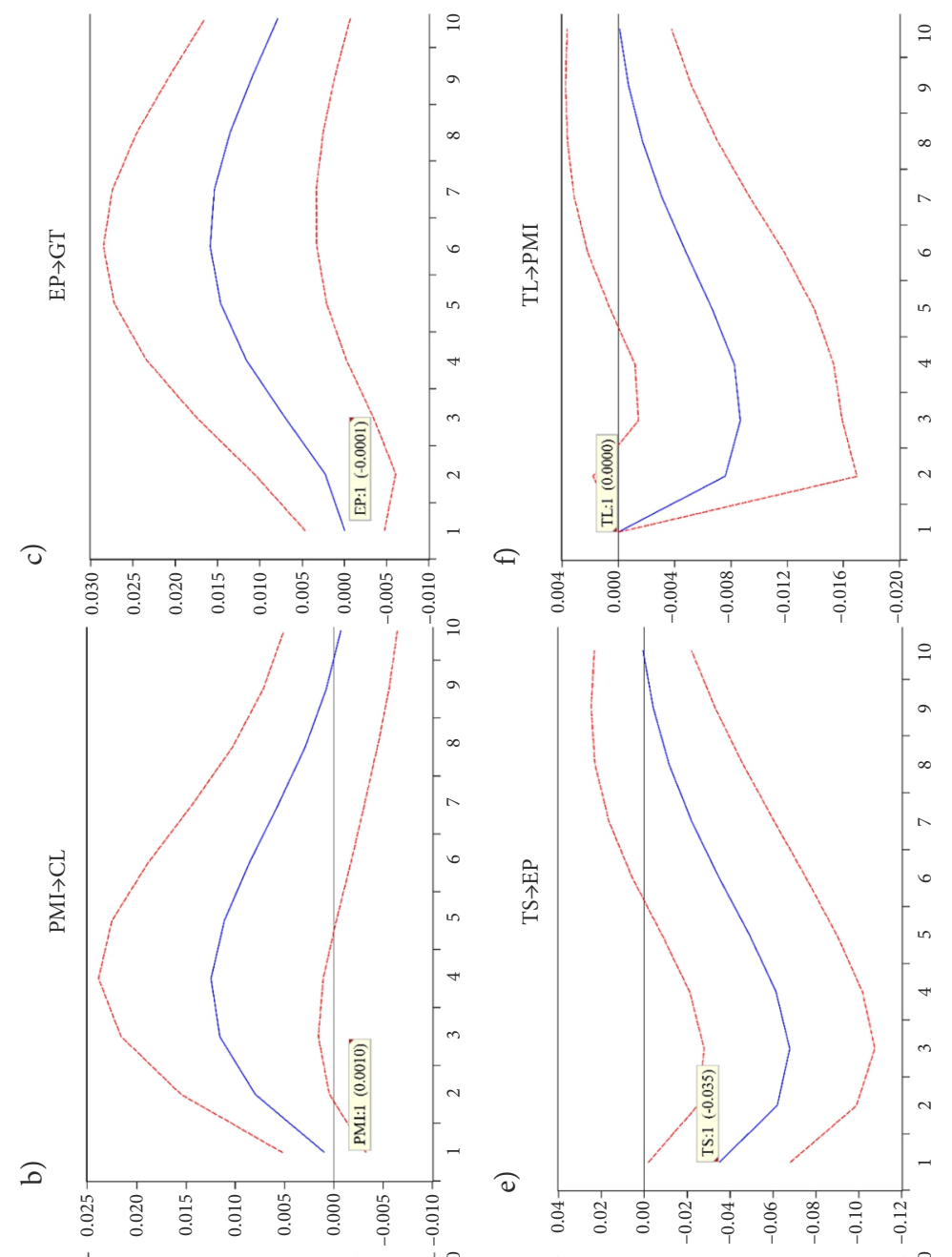

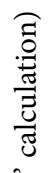
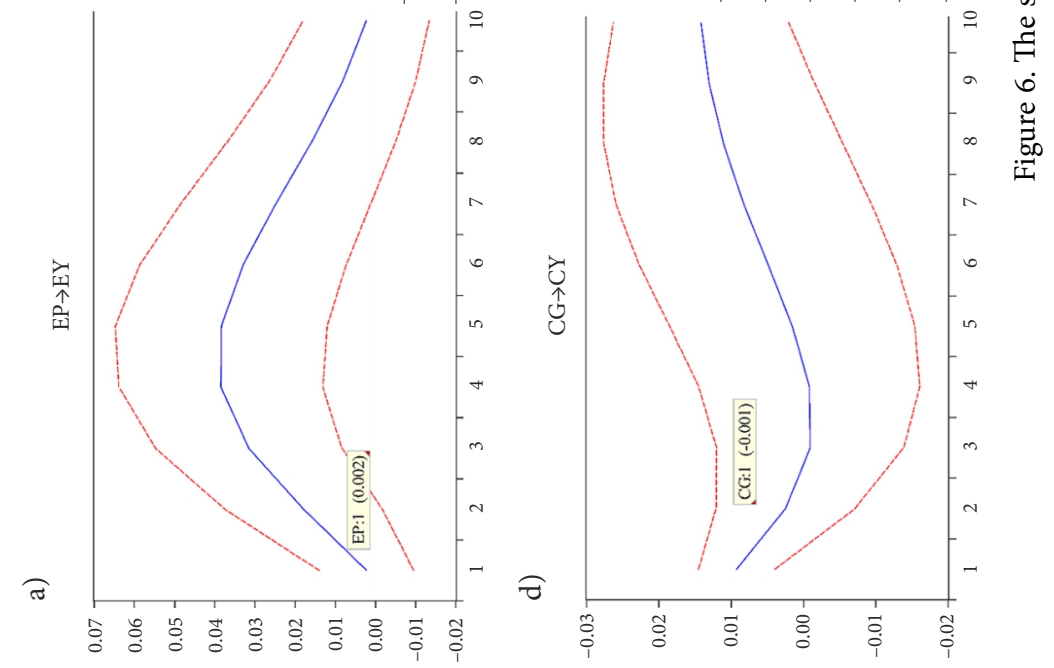
Table 5. Estimation results of the TVP-VAR model (source: authors' calculation)

\begin{tabular}{|c|c|c|c|c|c|c|}
\hline Parameter & Mean & Stdev & $95 \% \mathrm{U}$ & $95 \% \mathrm{~L}$ & Geweke & Inefficiency \\
\hline $\mathrm{sb} 1$ & 0.0031 & 0.0007 & 0.0020 & 0.0047 & 0.967 & 12.49 \\
\hline $\mathrm{sb} 2$ & 0.0031 & 0.0007 & 0.0020 & 0.0049 & 0.342 & 23.84 \\
\hline $\mathrm{sa} 1$ & 0.0055 & 0.0015 & 0.0034 & 0.0092 & 0.119 & 17.76 \\
\hline $\mathrm{sa} 2$ & 0.0056 & 0.0018 & 0.0034 & 0.0100 & 0.401 & 17.64 \\
\hline $\mathrm{sh} 1$ & 0.2728 & 0.0896 & 0.1449 & 0.4807 & 0.272 & 24.20 \\
\hline $\mathrm{sh} 2$ & 0.0055 & 0.0016 & 0.0034 & 0.0095 & 0.034 & 15.78 \\
\hline
\end{tabular}

the parameters converge to the posterior distribution, cannot be rejected at a $5 \%$ significance level (Geweke, 1991). Meanwhile, all the inefficiency factors are at a low level, less than 50. Thus, the estimation of the MCMC algorithm is effective and robust.

Figure 7 represents the autocorrelation coefficient, sample path and corresponding posterior density map. The autocorrelation coefficients of samples drop rapidly and tend to be stable, keeping it close to zero simultaneously. That is to say, the samples generated by the MCMC approach are not autocorrelated. The values of sample paths are steady, which shows that the sampled data are stable. Moreover, a significant wave and clustering phenomenon is performed in the chart for selected parameters. In summary, we can consider that the samples got in this paper are valid.

Figure 8 illustrates the time-varying impulse-response functions for a one-quarter ahead, a six-quarter ahead and a twelve-quarter ahead, respectively. On the one hand, whether it is short-term (one quarter), medium-term (six quarters) or long-term (twelve quarters), $P M I$ has a positive impact on "capital". Meanwhile, the short-term effects are the strongest, followed by the medium and long-term. The PMI's impact on "capital" has been slightly diminishing in terms of short and medium terms. No matter what period, $P M I$ negatively reacts to the "capital", and the short-term impact is the strongest. When one quarter is ahead, $P M I$ exerts a negative impact on "finance"; whereas, a positive impact is performed when six or twelve quarters are ahead. In particular, during the 2008 period (approximately $t=13$ ), a significant increase or decrease in the intensity of $P M I$ 's influence on "finance".

Figure 9 shows the time-varying impulse-response functions at distinct time points. In contrast to the above traditional impulse-response functions of the VAR model, the biggest dominance is that it can consider unique time points to display the responses based on the TVP-VAR model. In this way, the previous static impulse responses are complemented and strengthened. By setting unique time points, we can investigate the response of a given variable caused by shocks from another variable under a particular situation. The global financial crisis in $2008(t=13)$ and the stable period of the economy after $2012(t=30$ and $t=50)$ are selected to conduct a comparative analysis in this paper. In terms of $P M I$ and "capital", on the whole, $P M I$ generates a positive impact on "capital" and presents a phenomenon that strengthens first, and then slowly weaken until disappearing. However, it is worth noting that when the financial crisis broke out, the response effect of the exogenous shock of PMI to "capital" is stronger than in the normal state, at least in the first half of the period. Although "capital" hurts PMI, the influence of "capital" on PMI also shows the similar characteristics above. 

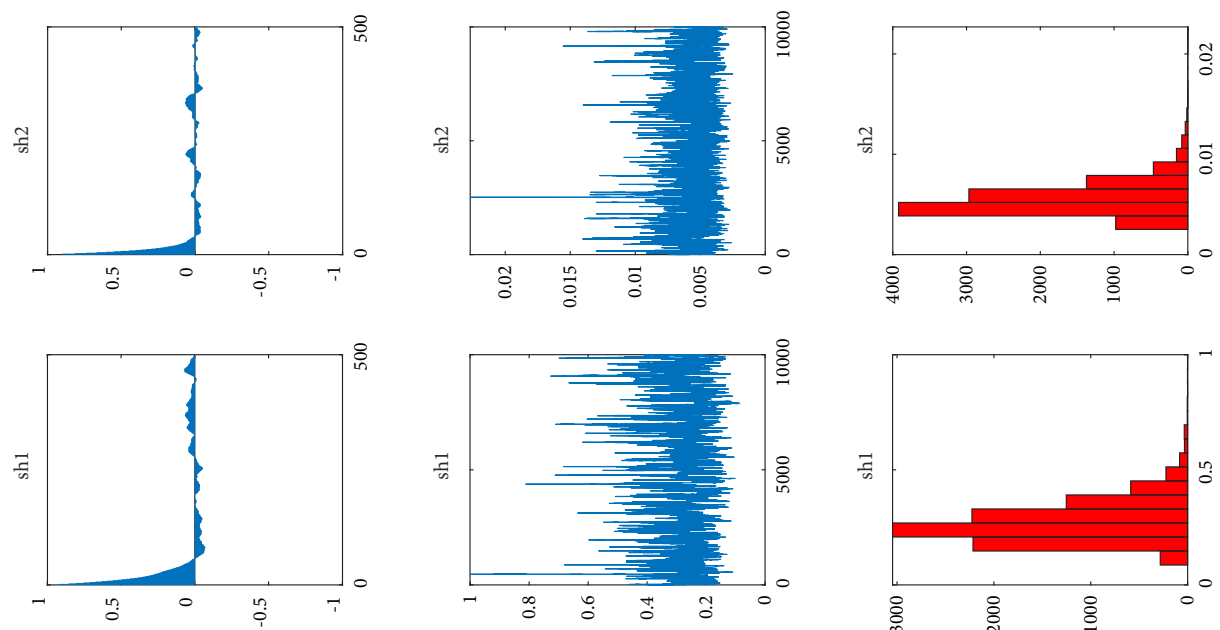

(3)
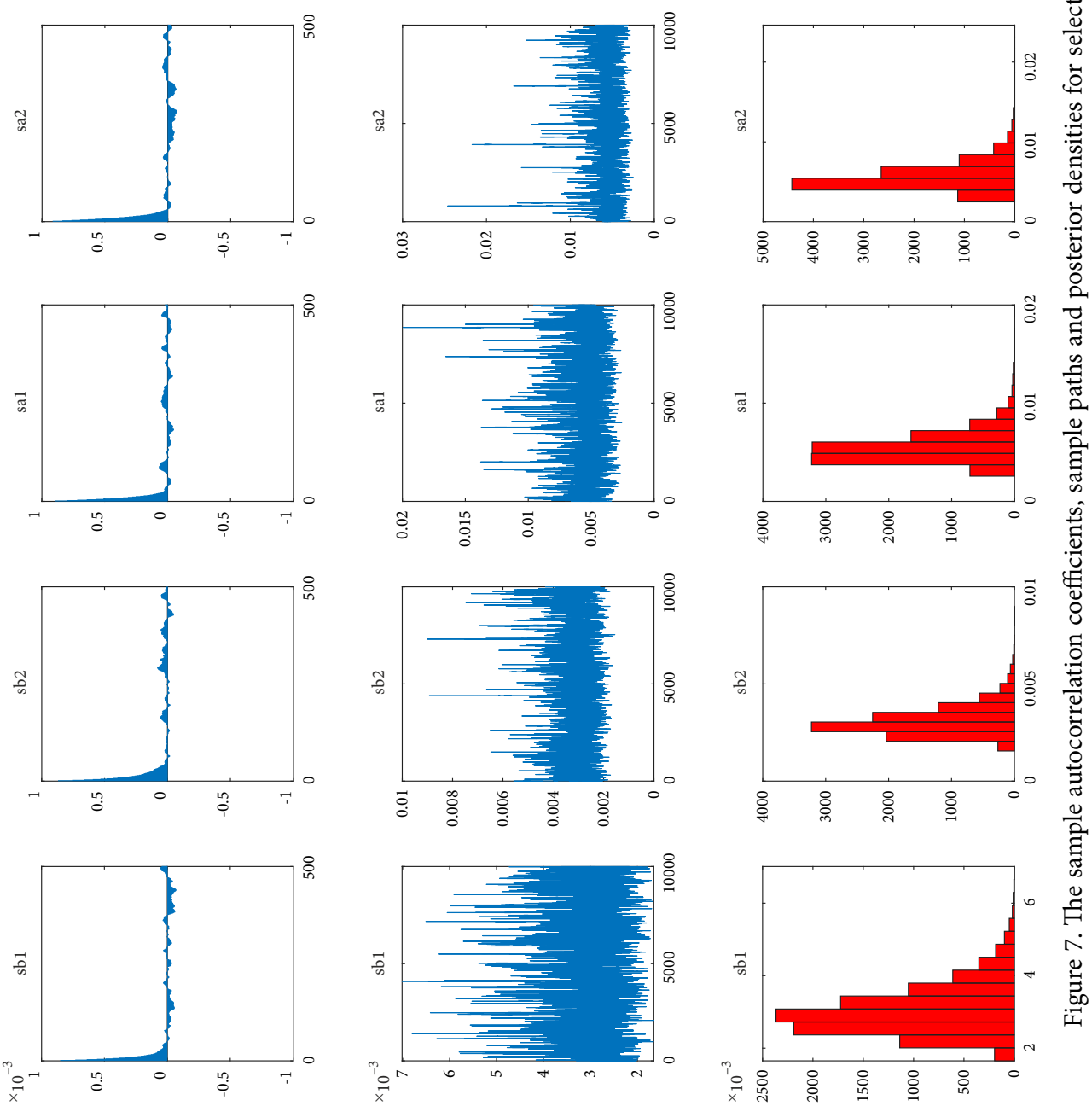

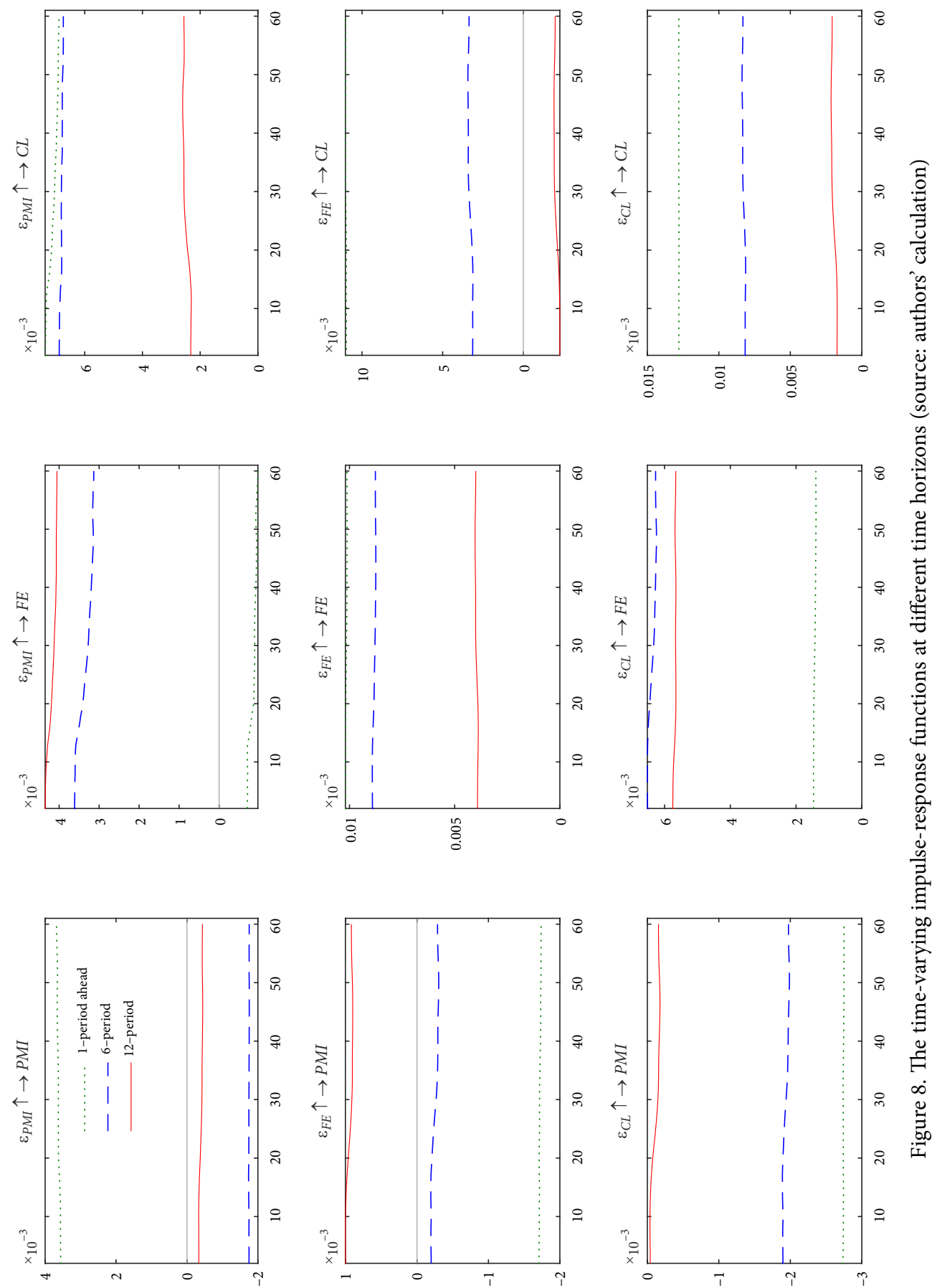

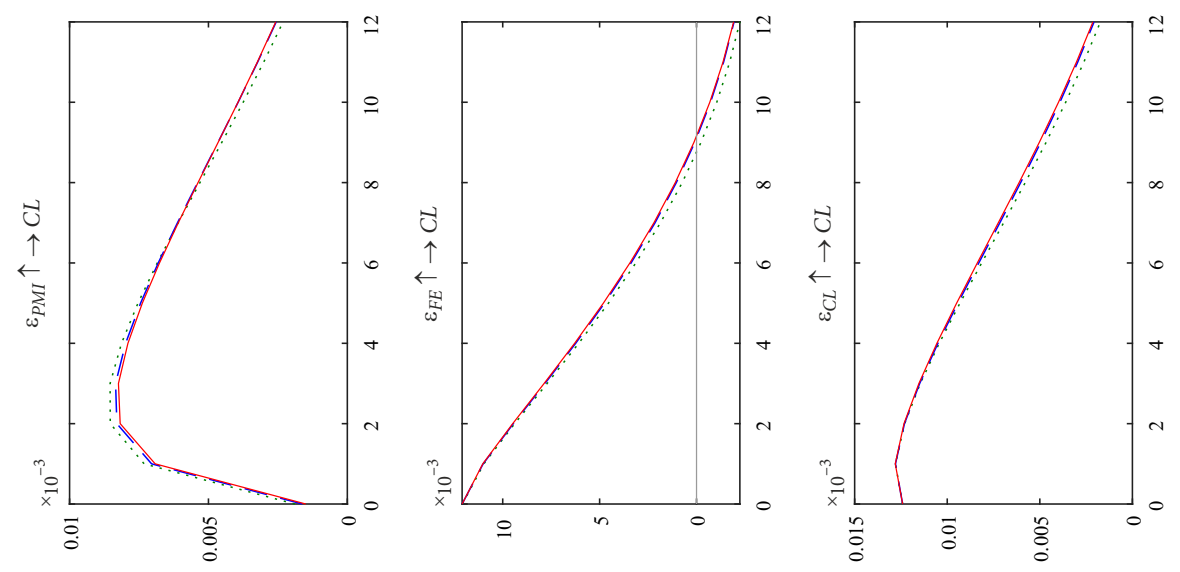

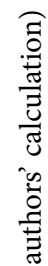
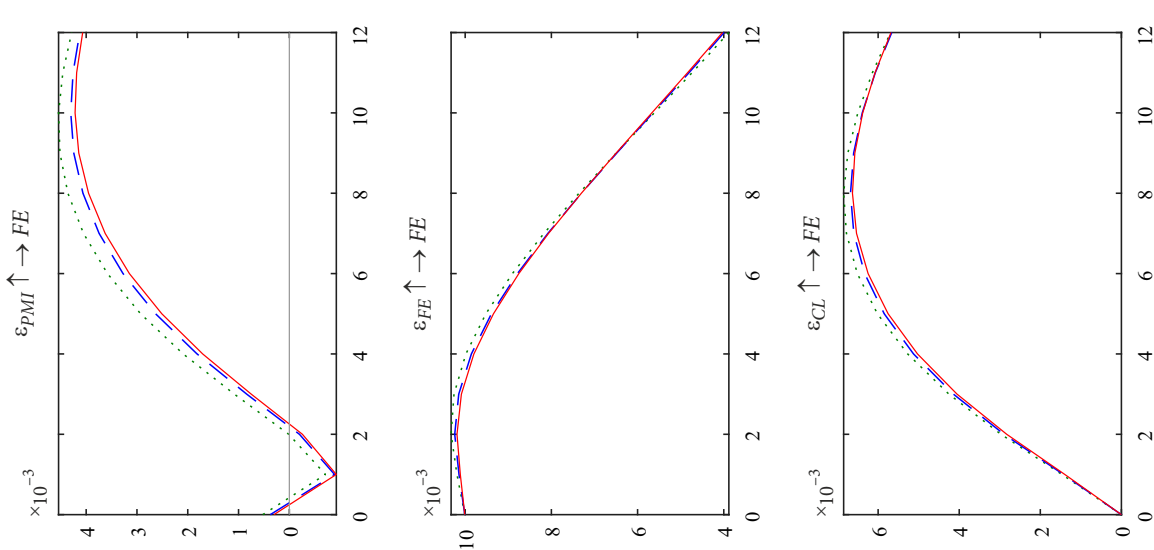

过 
For another, compared with the stable period of economy, the impact of $P M I$ on "finance" is more intense during the financial crisis. In the around first period, it falls at the beginning to its minimum, and then followed by a gradual rising trend and achieves a relatively steady state.

\subsection{Discussions}

This study sets out to examine whether financial cycles in scientific literature follow developments and trends in financial cycles in the economy. For this purpose, a descriptive analysis of economic research regarding financial cycles based on bibliometrics is performed to reveal our inference. As shown in Figure 2, several noticeable fluctuations and shifts occurred along with their movements from 1979 to 2019. In 1993, the first steep growth happened in the chart. Combined with the financial situation in China, an explanation for this might be a significant reform for the entire financial system. To establish a macro-control system for the central bank, i.e., the People's Bank of China independently implements monetary policies, a series of related measures were launched. Against this backdrop, the increase in financialrelated literature is not surprising. At the point of 1997, a smaller surge on academic work appears in contrast to that in 1993. The fact that the outbreak of the financial turmoil in Asia may explain this result. It damaged the financial and economic development of China to a certain extent. Many scholars actively offered suggestions for policymakers to stabilize the financial and economic situation. Naturally, the number of publications concerning financial cycles shows a clear upward trend. A violent rise occurs for almost series in approximately 2007, which easily reminds us of the global financial crisis triggered by the USA in 2007. This financial crisis lasted for three years, from 2007 to 2009, has inflicted heavy losses on China's economic development. To be specific, the economic growth of China slowed obviously during this period. The growth rate dropped from 13\% in 2007 to $9 \%$ in 2008, what is worse, further dropped to $8 \%$ in 2009 . It was not until 2010 that the economy presented signs of recovery. Policy responses run from all aspects of society. As a result, many research works are generated to bail the country out of financial struggle. There is a slight increase in the number of documents in about 2012. This result is likely to be related to the 12th Five-Year Plan's public announcement for the development and reform of the financial industry. Many finance academics would follow the guidance of the plan to carry out more meaningful and valuable research. Concurrently, the specific trends of 16 series in Figure 3 further display these characteristics.

In sum, the results of the above analysis intuitively show the comovement between financial cycles and scientific works. However, there are often some limitations in subjective judgment and analysis. On this account, we employ quantitative approaches to investigate their respective cycles and causalities between them. We carry out two further tasks in this paper. In the first place, the univariate cycles of financial and bibliometric variables are presented in Figure 4 and Figure 5. For one thing, the average cycle of six variables in China is around 4.7 years. For another, the average cycle of selected six terms in CNKI is approximately 5.3 years. Overall, it is easy to find that financial cycles in the economy and in economic research are almost the same. The slight time gap between them is because of the submission and 
publication process of journal articles. For nearly consistent cycles, this further confirms the synchronization of the fluctuations of financial and bibliometric data. Meanwhile, our speculation is also ulteriorly verified. Also, regardless of the financial cycles in reality or the literature, both are about five years. A possible explanation for this might be that the government in China sets the economic and financial plan every five years. Hence, policy plays a significant role in China's economics (Shen et al., 2019).

In the second place, the Granger causality test fully scrutinizes the results of descriptive analysis and cycles assessment. The 12 events of Granger causalities from financial variables to bibliometric ones show that financial cycles in the economy affect the development of financial research to a considerable degree. Besides, it is necessary to discuss the reverse and instantaneous Granger causalities found in this paper. We have to acknowledge the potential errors in data collection and variable settings. On the one hand, we convert annual data (i.e., bibliometric variables) into quarterly data because of the inconsistency of data frequency. Although this avoids the loss of observations, it also increases the experimental errors. On the other hand, the missing variable bias, whether financial or bibliometric, may cause the above test results.

For the appearance of reverse Granger causality, we can infer that there is a policy channel, through which, finance academics would form future financial policies and guidelines jointly with national managers. As a result, the bibliometric variables can affect the financial variables. Besides, we can think that financial texts could generate a "crisis", or at least could impact the financial situation to a certain extent. Even though the emergence of reverse causality contradicts our general cognition, it provides a rich ground for future research. Regarding the instantaneous Granger causality, this finding offers a soundproof for the interplay between financial development and scientific activity. There are two explanations for this result. One is that the prominent forecasting capacity for the relevant financial research can rapidly and promptly capture the patterns and trends in the financial data. Another is the "gathering effect" of journal articles when financial cycles occur. During the period of financial crises, journal editors are devoted to publishing articles related to the topic. When a financial downturn and many discussions on it coincide in a certain quarter, this may lead to the generation of instantaneous Granger causality.

In particular, the estimation of impulse-response functions provides a significant quantitative evaluation of the obtained Granger causalities. Under the framework of the VAR model, a positive or negative impulse is identified, and specific intensity can also be acquired, as illustrated in Figure 6. To examine whether the impulse of financial variables on literature ones at different time horizons or different time points is differentiating among other stable periods. Take the 2008 global financial crisis as an example, we implement a TVP-VAR analysis. Figure 8 and Figure 9 present the impulse-response functions of $P M I$ on "finance" and "capital" at different time horizons or points. The impulse at the time point in 2008 shows a significant change or more violent than other periods. This result straightforwardly states the impact of financial cycles on financial research. Overall, we use a combination of qualitative analysis and quantitative approaches in this investigation. The empirical findings strongly and fully attest that financial cycles in economic research are correlated with movements in actual financial activities. Our results are reasonably convincing and exciting. These results 
corroborate the findings of much of the previous work in earlier discussions. Nevertheless, we explore several interesting findings in this paper. For instance, the specific financial cycles in economic research are captured and identified. To a certain extent, it is a successful attempt and provides a new perspective and direction for future research.

\section{Conclusions}

Since 2008, financial cycles have become one of the most critical topics and engaged much attention in macroeconomics. Although there is a rich literature analyzing and characterizing financial cycles from various aspects, research has yet to provide a deeper insight into financial cycles in the literature and explore whether there is an interaction or even causality between financial cycles in the economy and in economic research. The goal of this paper is to fill this gap.

To this aim, we conduct a case study of China. First, we document scientific works (i.e., journal articles) related to financial cycles in CNKI to detect the developments and trends of academic work. It initially confirms the conjecture of this paper. Second, we witness the synchronization of financial cycles in reality and the literature. It should be pointed out that financial cycles in the literature is slightly longer than financial cycles in the economy. Third, we conduct formal econometric approaches to determine the causality between financial cycles in the economy and in economic research. As a result, 12 incidents of Granger causalities from financial variables to bibliometric ones, 16 events of reverse Granger causalities and 11 matters of instantaneous Granger causalities are found. Besides, the impulse-response functions and their variants (i.e., with time-varying characteristics) help us further quantify and understand the polarities (i.e., positive or negative) of impulse. These results suggest that there is an association between them.

It is essential to highlight the findings of reverse Granger causalities and instantaneous Granger causalities in this paper. We attempt to give a reasonable interpretation or speculation about this phenomenon, whereas more trials and works would help us have a deeper understanding of this matter. Concurrently, this finding would be a fruitful area for further work. However, the generalizability of these results is subject to certain limitations. For instance, we only apply the data from China to validate our assumption. Whether these conclusions are equally applicable to other regions or countries, which is still an issue to be tackled. Notwithstanding the relatively limited sample, this work offers valuable insights into financial cycles in economic research and their links with economy's financial cycles.

\section{Acknowledgements}

The work was supported by the National Natural Science Foundation of China (Nos. 71571123, 71771155 and 72101168$)$. 


\section{References}

Aikman, D., Haldane, A. G., \& Nelson, B. D. (2015). Curbing the credit cycle. The Economic Journal, 125(585), 1072-1109. https://doi.org/10.1111/ecoj.12113

Allen, M., \& Smith, L. (1996). Monte Carlo SSA: Detecting irregular oscillations in the Presence of Colored Noise. Journal of Climate, 9. https://doi.org/10.1175/1520-0442(1996)009<3373:MCSDIO>2.0.CO;2

Amiti, M., McGuire, P., \& Weinstein, D. E. (2019). International bank flows and the global financial cycle. IMF Economic Review, 67(1), 61-108. https://doi.org/10.1057/s41308-018-0072-6

Beirne, J. (2020). Financial cycles in asset markets and regions. Economic Modelling, 92, 358-374. https://doi.org/10.1016/j.econmod.2020.01.015

Berger, A. N., \& Udell, G. F. (1998). The economics of small business finance: The roles of private equity and debt markets in the financial growth cycle. Journal of Banking \& Finance, 22(6), 613-673. https://doi.org/10.1016/S0378-4266(98)00038-7

Boisjoly, R. P., Conine, T. E., \& McDonald, M. B. (2020). Working capital management: Financial and valuation impacts. Journal of Business Research, 108, 1-8. https://doi.org/10.1016/j.jbusres.2019.09.025

Borio, C. (2014). The financial cycle and macroeconomics: What have we learnt? Journal of Banking \& Finance, 45, 182-198. https://doi.org/10.1016/j.jbankfin.2013.07.031

Borio, C. (2017). Secular stagnation or financial cycle drag? Business Economics, 52, 1-12. https://doi.org/10.1057/s11369-017-0035-3

Brem, A., Nylund, P., \& Viardot, E. (2020). The impact of the 2008 financial crisis on innovation: A dominant design perspective. Journal of Business Research, 110, 360-369. https://doi.org/10.1016/j.jbusres.2020.01.048

Chen, H., Yang, Y., Yang, Y., Jiang, W., \& Zhou, J. (2014). A bibliometric investigation of life cycle assessment research in the web of science databases. The International Journal of Life Cycle Assessment, 19(10), 1674-1685. https://doi.org/10.1007/s11367-014-0777-3

Chen, W., Liu, W., Geng, Y., Brown, M. T., Gao, C., \& Wu, R. (2017). Recent progress on emergy research: A bibliometric analysis. Renewable and Sustainable Energy Reviews, 73, 1051-1060. https://doi.org/10.1016/j.rser.2017.02.041

Claessens, S., Kose, M. A., \& Terrones, M. E. (2011). Financial cycles: What? How? When? NBER International Seminar on Macroeconomics, 7(1), 303-344.

Costa, D. F., Carvalho, F. D., Moreira, B. C. D., \& do Prado, J. W. (2017). Bibliometric analysis on the association between behavioral finance and decision making with cognitive biases such as overconfidence, anchoring effect and confirmation bias. Scientometrics, 111(3), 1775-1799. https://doi.org/10.1007/s11192-017-2371-5

Colebrook, J. M. (1978). Continuous plankton records: Zooplankton and environment, North-East Atlantic and North Sea, 1948-1975. Oceanologica Acta, 1(1), 9-23.

Cortés-Sánchez, J. D. (2019). Innovation in Latin America through the lens of bibliometrics: Crammed and fading away. Scientometrics, 121, 869-895. https://doi.org/10.1007/s11192-019-03201-0

Demetrescu, C., Finocchi, I., Ribichini, A., \& Schaerf, M. (2020). On bibliometrics in academic promotions: A case study in computer science and engineering in Italy. Scientometrics. https://doi.org/10.1007/s11192-020-03548-9

Drehmann, M., Borio, C., \& Tsatsaronis, K. (2012). Characterising the financial cycle: Don't lose sight of the medium term! (BIS Working Papers No. 380, pp. 1-38).

Drehmann, M., Borio, C., \& Tsatsaronis, K. (2013). Can we identify the financial cycle? The role of central banks in financial stability how has it changed? Studies in International Economics, 30, 131-156. 
Elliott, G., Stock, J., \& Rothenberg, T. (1996). Efficient tests for an autoregressive unit root. Econometrica, 64, 813-836. https://doi.org/10.2307/2171846

Elsner, J. B. (2002). Analysis of time series structure: SSA and related techniques. Journal of the American Statistical Association, 97(460), 1207-1208. https://doi.org/10.1198/jasa.2002.s239

Farrell, G., \& Kemp, E. (2020). Measuring the financial cycle in South Africa. South African Journal of Economics. https://doi.org/10.1111/saje.12246

Fidrmuc, J., \& Korhonen, I. (2010). The impact of the global financial crisis on business cycles in Asian emerging economies. Journal of Asian Economics, 21(3), 293-303. https://doi.org/10.1016/j.asieco.2009.07.007

Geiger, N. (2014). The rise of behavioural economics: A quantitative assessment. In 18th Annual ESHET Conference on "Liberalisms: perspectives and debates in the history of economic thought" (pp. 29-31).

Geiger, N., \& Kufenko, V. (2016). Business cycles in the economy and in economics: an econometric analysis. Scientometrics, 107(1), 43-69. https://doi.org/10.1007/s11192-016-1866-9

Geweke, J. F. (1991). Evaluating the accuracy of sampling-based approaches to the calculation of posterior moments (Staff Report 148). Federal Reserve Bank of Minneapolis. https://ideas.repec.org/p/fip/fedmsr/148.html.

Ghil, M., Allen, M., Dettinger, M., Ide, K., Kondrashov, D., Mann, M., Saunders, A., Tian, Y., \& Varadi, F. (2001). Advanced spectral methods for climatic time series. Reviews of Geophysics, 40.

Granger, C. (1980). Testing for causality: A personal viewpoint. Journal of Economic Dynamics and Control, 2, 329-352. https://doi.org/10.1016/0165-1889(80)90069-X

Granger, C. W. J. (1969). Investigating causal relations by econometric models and cross-spectral methods. Econometrica, 37(3), 424-438. https://doi.org/10.2307/1912791

Groth, A., \& Ghil, M. (2015). Monte Carlo Singular Spectrum Analysis (SSA) revisited: Detecting oscillator clusters in multivariate datasets. Journal of Climate, 28(19), 7873-7893. https://doi.org/10.1175/JCLI-D-15-0100.1

Hodrick, R. J., \& Prescott, E. C. (1997). Postwar U.S. business cycles: An empirical investigation. Journal of Money, Credit and Banking, 29(1), 1-16.

Iacobucci, A. (2005). Spectral analysis for economic time series. Lecture Notes in Economics \& Mathematical Systems, 551, 203-219. https://doi.org/10.1007/3-540-28444-3_12

Inekwe, J. N., \& Valenzuela, M. R. (2020). Financial integration and banking crisis. A critical analysis of restrictions on capital flows. World Economy, 43(2), 506-527. https://doi.org/10.1111/twec.12855

Jetter, M., \& Kristoffersen, I. (2018). Financial shocks and the erosion of interpersonal trust: Evidence from longitudinal data. Journal of Economic Psychology, 67, 162-176. https://doi.org/10.1016/j.joep.2018.07.001

Jordà, Ò., Schularick, M., \& Taylor, A. M. (2013). When credit bites back. Journal of Money, Credit and Banking, 45(s2), 3-28. https://doi.org/10.1111/jmcb.12069

Juselius, M., Borio, C., Disyatat, P., \& Drehmann, M. (2016). Monetary policy, the financial cycle, and ultra-low interest rates. International Journal of Central Banking, 13, 55-89.

Lee, C.-C., Chen, M.-P., \& Ning, S.-L. (2017). Why did some firms perform better in the global financial crisis? Economic Research-Ekonomska Istrazivanja, 30(1), 1339-1366. https://doi.org/10.1080/1331677X.2017.1355258

Martínez-García, E., \& Grossman, V. (2020). Explosive dynamics in house prices? An exploration of financial market spillovers in housing markets around the world. Journal of International Money and Finance, 101, 102103. https://doi.org/10.1016/j.jimonfin.2019.102103

Mizen, P., \& Tsoukas, S. (2012). The response of the external finance premium in Asian corporate bond markets to financial characteristics, financial constraints and two financial crises. Journal of Banking \& Finance, 36(11), 3048-3059. https://doi.org/10.1016/j.jbankfin.2012.07.005 
Morana, C. (2017). The U.S. dollar/Euro exchange rate: Structural modeling and forecasting during the recent financial crises. Journal of Forecasting, 36(8), 919-935. https://doi.org/10.1002/for.2430

Mourao, P. R., \& Martinho, V. D. (2020). Forest entrepreneurship: A bibliometric analysis and a discussion about the co-authorship networks of an emerging scientific field. Journal of Cleaner Production, 256, 120413. https://doi.org/10.1016/j.jclepro.2020.120413

Muhammad, A., Ali, M. A. H., \& Shanono, I. H. (2020). ANSYS-A bibliometric study. Materials Today: Proceedings, 26(2), 1005-1009. https://doi.org/10.1016/j.matpr.2020.01.192

Nakajima, J. (2011). Time-varying parameter VAR model with stochastic volatility: An overview of methodology and empirical applications. Monetary and Economic Studies, 29, 107-142.

Nielsen, B. (2001). Order determination in general vector autoregressions. IMS Lecture Notes-Monograph Series, 52.

Ouyang, A. Y., \& Guo, S. (2019). Macro-prudential policies, the global financial cycle and the real exchange rate. Journal of International Money and Finance, 96, 147-167.

https://doi.org/10.1016/j.jimonfin.2019.05.009

Ozili, P. K. (2018). Impact of digital finance on financial inclusion and stability. Borsa Istanbul Review, 18(4), 329-340. https://doi.org/10.1016/j.bir.2017.12.003

Pagan, A., \& Robinson, T. (2014). Methods for assessing the impact of financial effects on business cycles in macroeconometric models. Journal of Macroeconomics, 41, 94-106.

https://doi.org/10.1016/j.jmacro.2014.04.002

Pinheiro, T., Rivadeneyra, F., \& Teignier, M. (2017). Financial development, credit, and business cycles. Journal of Money Credit and Banking, 49(7), 1653-1665. https://doi.org/10.1111/jmcb.12427

Pontines, V. (2017). The financial cycles in four East Asian economies. Economic Modelling, 65, 51-66. https://doi.org/10.1016/j.econmod.2017.05.005

Pragidis, I. C., Tsintzos, P., \& Plakandaras, B. (2018). Asymmetric effects of government spending shocks during the financial cycle. Economic Modelling, 68, 372-387. https://doi.org/10.1016/j.econmod.2017.08.005

Primiceri, G. E. (2005). Time varying structural vector autoregressions and monetary policy. The Review of Economic Studies, 72(3), 821-852. https://doi.org/10.1111/j.1467-937X.2005.00353.x

Qin, Y., Wang, X. X., Xu, Z. S., \& Škare, M. (2021). The impact of poverty cycles on economic research: evidence from econometric analysis. Economic Research-Ekonomska Istraživanja, 34(1), 152-171. https://doi.org/10.1080/1331677X.2020.1780144

Qin, Y., Xu, Z. S., Wang, X. X., \& Škare, M. (2020). Are family firms in the eyes of economic policy? International Entrepreneurship and Management Journal. https://doi.org/10.1007/s11365-020-00699-2

Rey, H. (2013). Dilemma not trilemma: the global cycle and monetary policy independence. Proceedings - Economic Policy Symposium - Jackson Hole, 1-2.

Rozite, K., Bezemer, D. J., \& Jacobs, J. P. A. M. (2019). Towards a financial cycle for the U.S., 1973-2014. The North American Journal of Economics and Finance, 50, 101023. https://doi.org/10.1016/j.najef.2019.101023

Schularick, M., \& Taylor, A. (2009). Credit booms gone bust: Monetary policy, leverage cycles, and financial crises, 1870-2008. American Economic Review, 102, 1029-1061. https://doi.org/10.1257/aer.102.2.1029

Schüler, Y. S., Hiebert, P. P., \& Peltonen, T. A. (2020). Financial cycles: Characterisation and real-time measurement. Journal of International Money and Finance, 100, 102082. https://doi.org/10.1016/j.jimonfin.2019.102082

Shen, C.-H., Shi, J.-G., \& Wu, M.-W. (2019). Is finance a veil? Lead-and-lag relationship between financial and business cycles: The case of China. European Financial Management, 25(4), 978-1012. https://doi.org/10.1111/eufm.12193 
Sims, C. A. (1980). Macroeconomics and Reality. Econometrica, 48(1), 1-48. https://doi.org/10.2307/1912017

Škare, M., \& Porada-Rochon, M. (2019). Tracking financial cycles in ten transitional economies 20052018 using singular spectrum analysis (SSA) techniques. Equilibrium-Quarterly Journal of Economics and Economic Policy, 14(1), 7-29. https://doi.org/10.24136/eq.2019.001

Škare, M., \& Porada-Rochoń, M. (2020). Multi-channel singular-spectrum analysis of financial cycles in ten developed economies for 1970-2018. Journal of Business Research, 112, 567-575. https://doi.org/10.1016/j.jbusres.2019.10.047

Strohsal, T., Proaño, C. R., \& Wolters, J. (2019a). Assessing the cross-country interaction of financial cycles: Evidence from a multivariate spectral analysis of the USA and the U.K. Empirical Economics, 57(2), 385-398. https://doi.org/10.1007/s00181-018-1471-2

Strohsal, T., Proaño, C. R., \& Wolters, J. (2019b). Characterizing the financial cycle: Evidence from a frequency domain analysis. Journal of Banking \& Finance, 106, 568-591. https://doi.org/10.1016/j.jbankfin.2019.06.010

Tunger, D., \& Eulerich, M. (2018). Bibliometric analysis of corporate governance research in Germanspeaking countries: Applying bibliometrics to business research using a custom-made database. Scientometrics, 117(3), 2041-2059. https://doi.org/10.1007/s11192-018-2919-Z

Tandon, A., Kaur, P., Mäntymäki, M., \& Dhir, A. (2021). Blockchain applications in management: A bibliometric analysis and literature review. Technological Forecasting and Social Change, 166, 120649. https://doi.org/10.1016/j.techfore.2021.120649

Vautard, R., \& Ghil, M. (1989). Singular spectrum analysis in nonlinear dynamics, with applications to paleoclimatic time series. Physica D: Nonlinear Phenomena, 35(3), 395-424. https://doi.org/10.1016/0167-2789(89)90077-8

Vautard, R., Yiou, P., \& Ghil, M. (1992). Singular-spectrum analysis: A toolkit for short, noisy chaotic signals. Physica D: Nonlinear Phenomena, 58(1), 95-126.

https://doi.org/10.1016/0167-2789(92)90103-T

Wang, X. X., Xu, Z. S., Su, S. F., \& Zhou, W. (2021). A comprehensive bibliometric analysis of uncertain group decision making from 1980 to 2019. Information Sciences, 547, 328-353.

https://doi.org/10.1016/j.ins.2020.08.036

Wen, F., Zhang, M., Deng, M., Zhao, Y., \& Ouyang, J. (2019). Exploring the dynamic effects of financial factors on oil prices based on a TVP-VAR model. Physica A: Statistical Mechanics and its Applications, 532, 121881. https://doi.org/10.1016/j.physa.2019.121881

Yu, D. J., Xu, Z. S., \& Saparauskas, J. (2019). The evolution of "Technological and Economic Development of Economy": A bibliometric analysis. Technological and Economic Development of Economy, 25(3), 369-385. https://doi.org/10.3846/tede.2019.10193

Yamani, E. (2019). Diversification role of currency momentum for carry trade: Evidence from financial crises. Journal of Multinational Financial Management, 49, 1-19. https://doi.org/10.1016/j.mulfin.2019.02.004

Yan, C., \& Huang, K. X. D. (2020). Financial cycle and business cycle: An empirical analysis based on the data from the U.S. Economic Modelling, 93, 693-701. https://doi.org/10.1016/j.econmod.2020.01.018

Yépez, C. A. (2018). Financial intermediation and real estate prices impact on business cycles: A Bayesian analysis. The North American Journal of Economics and Finance, 45, 138-160. https://doi.org/10.1016/j.najef.2018.02.006

Zouri, S. (2020). Business cycles, bilateral trade and financial integration: Evidence from economic community of West African states (ECOWAS). International Economics, 163, 25-43. https://doi.org/10.1016/j.inteco.2020.04.001 